\title{
Prebiotic effects of olive pomace powders in the gut: In vitro evaluation of the inhibition of adhesion of pathogens, prebiotic and antioxidant effects
}

\author{
Tânia Bragança Ribeiro ${ }^{\mathrm{a}, \mathrm{b}}$, Célia Maria Costa ${ }^{\mathrm{a}}$, Teresa Bonifácio - Lopes ${ }^{\mathrm{a}}$, Sara Silva ${ }^{\mathrm{a}}$, \\ Mariana Veiga $^{a}$, Ana Rita Monforte ${ }^{\mathrm{a}}$, João Nunes ${ }^{\mathrm{b}}$, António A. Vicente ${ }^{\mathrm{c}}$, Manuela Pintado ${ }^{\mathrm{a}, \mathrm{*}}$

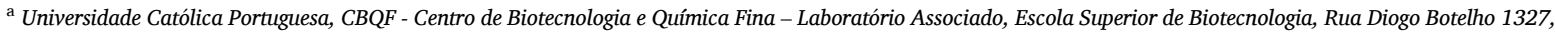 \\ 4169-005, Porto, Portugal \\ ${ }^{\mathrm{b}}$ Association BLC3 - Technology and Innovation Campus, Centre Bio R\&D Unit, Rua Nossa Senhora da Conceição, 2, Lagares, 3405-155, Oliveira do Hospital, Portugal

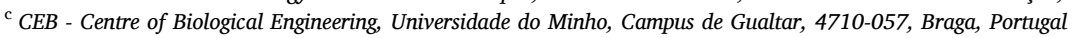

\section{A R T I C L E I N F O}

\section{Keywords:}

Olive pomace

Biowaste

Dietary fibre

Prebiotic effect

Antioxidant activity

Gut health

\begin{abstract}
A B S T R A C T
Olive pomace is a biowaste rich in polyphenols and insoluble dietary fibre with high potential to develop new value chains towards a sustainable and circular bioeconomy. Regarding gut health, olive pomace phenolics and insoluble dietary fibre (after possible fermentation) could act as antioxidants, antimicrobial and prebiotic agents. These potential beneficial effects on the gut were analysed for two powders from olive pomace: liquid-enriched powder (LOPP) - mostly source of phenolics - and pulp-enriched powder (POPP) - main source of insoluble dietary fibre. LOPP and POPP were subjected to an in vitro simulated gastrointestinal digestion followed by in vitro faecal fermentation. The undigested fraction retained in the colon was analysed regarding its potential antioxidant, antimicrobial and prebiotic effects. LOPP and POPP did not impact the gut microbiota diversity negatively, showing a similar ratio of Firmicutes/Bacteroidetes compared to a positive control (FOS). LOPP exhibit a positive (similar to FOS) effect on the Prevotella spp./Bacteroides spp. ratio. Both powders promoted more the production of short-chain fatty acids (mainly acetate $>$ butyrate $>$ propionate) than FOS and showed also significant total phenolic content and oxygen radical absorbance capacity during faecal fermentation until $48 \mathrm{~h}$. Besides that, these powders showed mucin-adhesion inhibition ability against pathogens, principally POPP against Bacillus cereus $(22.03 \pm 2.45 \%)$ and Listeria monocytogenes $(20.01 \pm 1.93 \%)$. This study demonstrates that olive pomace powders have prebiotic effects on microbiota, including the stimulation of short-chain fatty acids production, potential antioxidant and antimicrobial activity which could improve the human gut health.
\end{abstract}

\section{Introduction}

Sustainable and functional ingredients have been developed from several food by-products. This trend towards a circular economy model has been rising as an opportunity to manage the environmental and nutritional problems of today's society, also allowing the generation of economic gains for the food industry (Torres-León et al., 2018). Presently, there is a stimulus to reduce the disposal of olive oil production by-products, specifically the olive pomace (OP), which represents the major environmental problem and cost of this industry (Conterno et al., 2019).

OP has been extensively investigated to obtain new functional and bioactive ingredients due to its richness in olive oil phenolics (Nunes et al., 2016). Recently, OP dietary fibre (DF) has also been explored
(Galanakis, 2011; Ying et al., 2017). However, until now, these functional ingredients have been developed involving the use of organic solvents or requiring higher operational costs and valorising only a small fraction of the OP. So, to fulfil this lack, we have developed a liquid-enriched olive pomace powder (LOPP) and pulp-enriched olive pomace powder (POPP). These OP powders have been described as important sources of DF, olive oil phenolics and soluble sugars (Ribeiro et al., 2020). If LOPP is mainly a source of phenolics and sugars, POPP contains a significant amount of insoluble dietary fibre (IDF), mainly constituted by lignin but also cellulose, hemicellulose and bound phenolics associated with DF.

The main OP powder phenolics (hydroxytyrosol and derivatives) were known to have several health benefits linked to cardiovascular disease prevention (Robles-Almazan et al., 2018) (e.g. protectors from

\footnotetext{
* Corresponding author.

E-mail address: mpintado@porto.ucp.pt (M. Pintado).
} 
oxidative damage of low-density lipoprotein (LDL) particles (EFSA, 2011)). However, OP phenolics have also been described as antimicrobial agents against both Gram-positive/Gram-negative bacteria and stimulants of the growth of beneficial bacteria in the gut (KarkovićMarković et al., 2019; Mosele et al., 2014). Not only DF and its associated bound phenolics, often referred to as non-digestible polysaccharides, may remain unaltered until reaching the colon (Arranz et al., 2010; Papillo et al., 2014; Sato et al., 2011), but also not all polyphenols are absorbed in the small intestine and could reach the colon (Mosele et al., 2014). In the gut, DF and phenolics could be fermentable and undergo biotransformation by the gut microbiota (Lattimer \& Haub, 2010; Williams et al., 2017) increasing the beneficial bacteria content, the short-chain fatty acids (SCFAs) production and exerting other potential health benefits associated to phenolics action (Arranz et al., 2010; Papillo et al., 2014; Sato et al., 2011).

The literature supported the prebiotic potential of OP powders. According to the most recent definition of 'prebiotic' proposed by ISAPP consensus panel as 'a substrate that is selectively utilised by host microorganisms conferring a health benefit', other substances such as polyphenols and not only the usual carbohydrate-based compounds, might fit the updated definition, assuming adequate evidence of health benefit for the target host (Gibson et al., 2017). Phenolic compounds were pointed as potential prebiotic candidates, with enhancer benefits on microbiota composition, gut permeability and anti-inflammatory/immunity mechanisms (Papillo et al., 2014; Williams et al., 2017). However, far more studies in the target host are required to validate phenolic 'prebiotic effects' (Gibson et al., 2017). In conclusion, prebiotics are compounds that have the potential to improve human health and reduce the risk of diseases mediated by microbiota dysbiosis (Gibson et al., 2017).

The specific stimulation of the growth and/or activity of intestinal bacteria associated with health and well-being was considered a 'prebiotic effect'. In this field, the sequencing techniques, especially $16 \mathrm{~S}$ rRNA-based approaches, have been revolutionising the study of changes in human faecal microbial communities (Wang et al., 2019). On the other hand, the release of SCFAs (acetate, propionate and butyrate) as a result of microbial fermentation of phenolics and DF, if measurable, as distinct from a control, could also constitute a 'prebiotic effect'. These SCFAs are metabolised by the colonic epithelium (butyrate), liver (propionate) and muscle (acetate), exerting different functions with an essential role in health and disease (Laparra \& Sanz, 2010). At the same time, an increase in the antioxidant phenolic compounds generated as microbial metabolites could also be found with the potential to decrease the local oxidative stress. So, besides the 'prebiotic effects', phenolics could also exert potential antioxidant and/or antimicrobial effects (against pathogens) on the gut.

The impact of the gastrointestinal tract on OP powders, regarding the recovery and bioaccessibility of bioactive compounds, has been assessed (Ribeiro et al., 2020). However, the potential beneficial effect on the gut of DF and phenolics (free and bound form) retained in significant amounts in the colon fraction has not been disclosed yet. Few studies have analysed the potential prebiotic and antioxidant impact on the gut microbiota of olive oil (Liehr et al., 2017; Mosele et al., 2014; Santos et al., 2012) and olive leaf extracts (Aponte et al., 2018; Haddadin, 2010), but until now the influence of OP on the composition of human gut microbiota was only assessed by Conterno et al. (2019). In this study, the 16S rRNA gene analysis allowed to validate that OP incorporated into biscuits did not impact negatively on the diversity of the faecal microbiota. The effect of the OP oil as a dietary supplement on the rumen microbial community profile in Comisana ewes was also investigated decreasing the population of lipase-producing microorganisms (Anaerovibrio spp.), lipolysis rate and the concentration of polyunsaturated fatty acids involved in biohydrogenation (Mannelli et al., 2018).

According to our knowledge, there are no studies where the OP food ingredients prebiotic potential was assessed by in vitro fermentation with faecal inocula. Therefore, for the first time, the present study intends to analyse the potential prebiotic effect of OP powders and their potential antioxidant and antimicrobial effects on gut health. Not only the OP powders capacity to modulate the gut microbiota composition and its metabolic activity were studied by copy of the 16S rRNA gene of the bacterial population and quantifying the amount of SCFAs produced after the in vitro colonic fermentation, but also their ability to create an antioxidant environment in the gut by liberation of phenolic metabolites (LC-ESI-UHR-QqTOF-MS) and to inhibit the adhesion of pathogens (antiadhesion ability) were assessed. In short, a complete in vitro screen of the OP powders potential as prebiotics and gut-health benefits ingredients is aimed in this study.

\section{Materials and methods}

\subsection{Preparation of olive pomace powders}

OP was collected from an olive mill from Oliveira do Hospital, Portugal, being composed mainly by the olive cultivar Galega Vulgar ( $80 \%$ of the olive heritage). Samples from different hours of the day of the olive oil production were taken and transported to the laboratory, where they were mixed. The homogenous sample obtained from this procedure was packed in polyethene flasks and kept in a freezer at $80{ }^{\circ} \mathrm{C}$ until use to minimise polyphenols damage.

OP was fractionated by centrifugation $(10,000 \mathrm{~g}$ for $10 \mathrm{~min})$. The liquid fraction was freeze-dried (Telstar Lyo Quest HT 40) with $2 \%$ of mannitol (as a cryoprotectant and to prevent aggregation), and the powder obtained was denominated liquid-enriched olive pomace powder (LOPP). The solid fraction was oven-dried $\left(90^{\circ} \mathrm{C}\right.$, water activity $<$ 0.4, $90 \mathrm{~min}$ ), milled using a coffee grinder and sieved (mesh 40). All the pieces of stones were removed to obtain a potentially food-grade ingredient free of the small stones, which is a potential physical hazard. This fraction was denominated pulp-enriched olive pomace powder (POPP).

\subsection{Simulated in vitro gastrointestinal digestion and large intestine fermentation model}

POPP and LOPP in vitro simulations of gastrointestinal digestion (SGD) were performed according to the method that includes the dialysis process in order to simulate intestinal and blood absorption described by (Ribeiro et al., 2020). Mouth digestion was conducted with $0.6 \mathrm{~mL}$ of $100 \mathrm{U} / \mathrm{mL} \alpha$-amylase solution (Sigma) and incubation took place for $1 \mathrm{~min}$, at $37{ }^{\circ} \mathrm{C}$ and $200 \mathrm{rpm}$. For gastric digestion, the $\mathrm{pH}$ was adjusted to 2.0 with concentrated $\mathrm{HCl}\left(1 \mathrm{~mol} \mathrm{~L}^{-1}\right)$, and the mixture was incubated with $25 \mathrm{mg} / \mathrm{mL}$ of pepsin (from porcine stomach mucosa, pepsin A $250 \mathrm{U} / \mathrm{mg}$, Sigma), at a rate of $0.05 \mathrm{~mL} / \mathrm{mL}$ of sample, in a shaking bath, for $60 \mathrm{~min}$ at $37^{\circ} \mathrm{C}$. Intestinal digestion was performed by adjusting pH to 6.0 with $\mathrm{NaHCO}_{3}\left(1 \mathrm{~mol} \mathrm{~L}^{-1}\right)$, before the addition of $2 \mathrm{~g}$ $\mathrm{L}^{-1}$ of pancreatin (from porcine pancreas $8 \times$ USP, Sigma) and $12 \mathrm{~g} \mathrm{~L}^{-1}$ of bile salts (Sigma), at a ratio of $0.25 \mathrm{~mL} / \mathrm{mL}$ of sample, and further incubation of the mixture for an additional $120 \mathrm{~min}$ at $37^{\circ} \mathrm{C}$. In the last phase of intestinal digestion, a segment $(10 \mathrm{~cm})$ of dialysis tubing $(3.5$ $\mathrm{kDa}$ molecular weight cut-off) filled with $\mathrm{NaHCO}_{3}\left(1 \mathrm{~mol} \mathrm{~L}^{-1}\right)$ was placed inside of screw-topped bottles filled with digested samples and incubated for $2 \mathrm{~h}$ in a shaking water bath, at $37^{\circ} \mathrm{C}$ and $50 \mathrm{rpm}$.

At the end of the incubation process, the solution left outside the dialysis tubing (OUT) represented the non-absorbable sample (colonavailable). The OUT sample was homogenised and partitioned in two portions. One portion was centrifuged for $12 \mathrm{~min}$ at $8000 \mathrm{~g}$ at $4{ }^{\circ} \mathrm{C}$, yielding the soluble fractions and the pellet fractions. Soluble fractions were lyophilised and used to evaluate the antiadhesion ability. The other OUT portion was lyophilised and then exposed to faecal fermentation using fresh faecal inoculum (maintained under anaerobic conditions, for a maximum of $2 \mathrm{~h}$ before being used) obtained from five healthy donors (A-E, two men and three women, ages between 23 and 63 years old) according to the methodology developed by Gullon et al. (2015) and 
Gullón et al. (2014). The faecal inocula (FI) were prepared in an anaerobic workstation by diluting $\left(100 \mathrm{~g} \mathrm{~L}^{-1}\right)$ the faecal matter in Reduced Physiological Salt solution (RPS) (constituted by $0.5 \mathrm{~g} \mathrm{~L}^{-1}$ cysteine-HCl (Merck, Darmstadt, Germany) and $8.5 \mathrm{~g} \mathrm{~L}^{-1} \mathrm{NaCl}$ (LabChem, Zelienople, USA) with a final pH value of $6.8\left(10 \% \mathrm{CO}_{2}, 5 \% \mathrm{H}_{2}\right.$ and $85 \% \mathrm{~N}_{2}$ ). The flasks containing $50 \mathrm{~mL}$ of Nutrient Base Medium (NBS - Procedure of preparation in Supplementary material A1) were capped and autoclaved. Following sterilisation, and before adding the faecal inocula, the freeze-dried digested olive pomace powders biomass were added to the respective vessels at a final concentration of 20 g.L ${ }^{-1}$. In other flasks, fructooligosaccharides (FOS) (Nutripar, Matosinhos, Portugal) in the same concentration as a positive control were added. FOS are well-known prebiotics, which is often used to be positive controls in fermentation experiments in vitro. Flasks without substrate only NBS $(60 \mathrm{~mL})$ were used as blanks. Then, the atmosphere of each flask was refluxed with a gas mixture $\left(10 \% \mathrm{CO}_{2}, 5 \% \mathrm{H}_{2}\right.$ and $\left.85 \% \mathrm{~N}_{2}\right)$ sterilised using a $0.22 \mu \mathrm{m}$ filter (Millipore, Burlington, USA) followed by inoculation at $2 \%(\mathrm{v} / \mathrm{v})$ with $\mathrm{FI}$ and incubated for $48 \mathrm{~h}$ at $37{ }^{\circ} \mathrm{C}$ under anaerobic atmosphere $\left(10 \% \mathrm{CO}_{2}, 5 \% \mathrm{H}_{2}\right.$ and $\left.85 \% \mathrm{~N}_{2}\right)$. Samples were collected after $0,12,24$ and $48 \mathrm{~h}$ of incubation $(4 \mathrm{~mL}$ ) and the $\mathrm{pH}$ values were measured using a MicropH $2002 \mathrm{pH}$ meter (Crison, Barcelona, Spain), equipped with a 52-07 pH electrode (Crison, Barcelona, Spain). The positive control and blank were respectively designated as FOS and Blank (only faecal inocula), while the powders obtained from the olive pomace digested were dubbed as POPP for pulp-enriched powder and LOPP for liquid-enriched powder. Afterwards, the samples were stored at $-30{ }^{\circ} \mathrm{C}$ until analysis. All the steps considered in this section were carried out inside an anaerobic workstation (Don Whitley Scientific, West Yorkshire, UK).

Aliquots (4 mL) of each sample collected were centrifuged for $6 \mathrm{~min}$. The resulting pellet was used to extract the genomic DNA. On the other hand, the supernatants were used to evaluate short-chain fatty acid (SCFA) production, the amount of total phenolic acids (TPC), identification of phenolic acids and its metabolites and even the potential antioxidant activity (AOX).

\subsection{Bacterial population analysis}

\subsubsection{DNA extraction and real-time quantitative polymerase chain reaction}

DNA was extracted using an NZY Tissue gDNA Isolation kit (NZYTech, Lisbon, Portugal) according to the manufacturers' instructions, with some adaptations (Supplementary Material A2). Afterwards, copy numbers of the 16S rRNA gene from the Firmicutes, Lactobacillus spp., Enterococcus spp., Clostridium leptum, Bacteroidetes, Bacteroides spp., Prevotella spp., and Bifidobacterium spp. groups were determined using primers obtained from STABvida (Lisbon, Portugal), according to a realtime polymerase chain reaction (RT-PCR) using a CFX96 Touch $^{\mathrm{TM}}$ RealTime PCR Detection System (Bio-Rad Laboratories, Inc., Hercules, USA), under conditions adapted from Marques et al. (2016) and detailed in Supplementary Material A2.

\subsection{Short-chain fatty analysis}

Short-chain and branched-chain fatty analysis were determined in supernatants resulted from the faecal fermentation (Gullon et al., 2015). The analyses were performed using a Beckman Coulter System Gold HPLC (Knauer, Berlin, Germany) coupled to IR and UV detector using Aminex 37-H column (Bio-rad, Berkeley, USA) at $55^{\circ} \mathrm{C}$ and $35 \mathrm{mmol} \mathrm{L}^{-1}$ $\mathrm{H}_{2} \mathrm{SO}_{4}$ as mobile phase (flow rate: $0.5 \mathrm{~mL} / \mathrm{min}$ ). The identification and quantification were achieved by comparison of the relative retention times of sample peaks with standards and using a calibration curve in the range of concentrations of $0.2-2.0 \mathrm{mg} \mathrm{mL}^{-1}$.

\subsection{Phenolic compounds analysis}

\subsubsection{Total phenolic compounds and antioxidant activity}

The total phenolic content (TPC) of supernatants were determined according to the Folin-Ciocalteu method (Oliveira et al., 2016; Singleton \& Rossi, 1965). Results were expressed as mg gallic acid equivalents (GAE)/g of dry weight (DW).

The antioxidant activity (AOX) of supernatants of each OP powder and controls throughout the faecal fermentation was achieved according to the methods of ORAC (Costa et al., 2019) using a multidetection plate reader (Synergy H1, Vermont, USA). The radical stock solutions were freshly prepared. All analyses were performed in triplicate and expressed in $\mu \mathrm{mol} \mathrm{L}^{-1}$ of Trolox-equivalents (TE)/g DW.

\subsubsection{Identification of phenolic compounds by LC-ESI-UHR-QqTOF-MS}

The complete profile of phenolic compounds and its derivatives in supernatants of faecal fermentation of three donors were analysed in an LC-ESI-UHR-QqTOF-MS following the methodology of Monforte et al. (2018). Identification of main olive phenolic compounds was based on the retention time, UV-Vis and mass spectra with those obtained from the standard solutions, when available. The other peaks were tentatively identified comparing the information with available data reported in the literature (Ribeiro et al., 2020). Data from Phenol-Explorer 3.6 listed under "polyphenol metabolites" (http://phenol-explorer.eu/metabolite s) was used as a reference for compound identification. The elemental composition for compounds was confirmed according to accurate mass (5 mDa), and isotope rate calculations designated mSigma $(<20)$ (Bruker Daltonics).

Phenolic metabolites that passed the mass accuracy and frequency of detection thresholds, that had plausible chromatogram peak features, and that showed significantly different trends from the control (faeces only), were considered as potential polyphenol fermentation markers.

\subsection{Evaluation of the antiadhesion ability in mucin}

The Gram-positive food contaminant/pathogenic bacteria (Bacillus cereus ATCC 2599 and Listeria monocytogenes 13562) and Gram-negative food contaminant/pathogenic bacteria (Yersinia enterocolitica NCTC 10406 and Escherichia coli ATCC 25922) were used to study the antiadhesion ability of OP powders digested. Suspensions of overnight cultures were adjusted to a final concentration of $10^{8}$ colony forming units $(\mathrm{CFU}) / \mathrm{mL}$ on a DEN-1 McFarland densitometer (Biosan, Latvia). The antiadhesion ability was estimated according to a modified method of Valeriano et al. (2014) and Vunduk et al. (2019). Antiadhesion assays were performed in flat bottomed 96-well polystyrene microtitre plates (Tissue Culture Testplate; SPL Life Sciences, Pocheon, Korea) using pig ileal mucin ( $1 \mathrm{mg} \mathrm{mL}^{-1}$ and) as a matrix. Approximately $100 \mu \mathrm{L}$ of mucin solution $\left(1 \mathrm{mg} \mathrm{mL}^{-1}\right)$ in $10 \mathrm{mmol} \mathrm{L-1}$ phosphate-buffered saline (PBS) buffer was immobilised on the plate wells for $1 \mathrm{~h}$ and subsequently incubated overnight at $4{ }^{\circ} \mathrm{C}$. Wells were washed twice with $200 \mu \mathrm{L}$ PBS buffer and incubated with $100 \mu \mathrm{L}\left(20 \mathrm{mg} \mathrm{mL}^{-1}\right)$ bovine serum albumin (BSA) (Sigma) for $2 \mathrm{~h}$ at $4{ }^{\circ} \mathrm{C}$. Wells were again washed twice with 200 $\mu \mathrm{L}$ of PBS buffer to remove unbound BSA. Approximately $50 \mu \mathrm{L}$ of

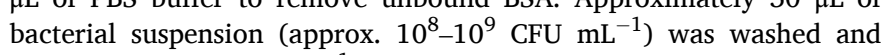
suspended in $10 \mathrm{mmol} \mathrm{L}^{-1}$ PBS buffer and added to the wells. Additionally, in control samples, $50 \mu \mathrm{L}$ of PBS and to OP samples $50 \mu \mathrm{L}$ of each OP powder $(2 \% \mathrm{~m} / \mathrm{v})$ were added. Then plates were incubated at $37^{\circ} \mathrm{C}$ for $1 \mathrm{~h}$. After incubation, wells were washed five times with $200 \mu \mathrm{L}$ sterile citrate buffer to remove unbound bacteria. Another $200 \mu \mathrm{L}$ of $0.5 \%(\mathrm{v} / \mathrm{v})$ Triton X-100 was then added to isolate attached bacteria. The viable cell count expressed as $\mathrm{CFU} \mathrm{mL}{ }^{-1}$ was determined in all cases by plating on specific media. Each assay was performed in triplicate with each trial having more than two replicates each. The percentage of inhibition of bacterial adhesion in the presence of OP powders was calculated as: 
Table 1

Values of $\log 16 \mathrm{~S}$ rRNA gene copies/ng of DNA of gut bacterial population sizes after 12, 24 and $48 \mathrm{~h}$ of the in vitro faecal fermentation of OP powders.

\begin{tabular}{|c|c|c|c|c|c|c|c|c|c|c|c|}
\hline \multirow[t]{3}{*}{ Samples } & \multirow[t]{3}{*}{ Time (h) } & \multicolumn{10}{|l|}{ Gut microbiota } \\
\hline & & \multicolumn{4}{|l|}{ Phylum Firmicutes } & \multicolumn{3}{|c|}{ Phylum Bacteroidetes } & \multirow{2}{*}{$\frac{\text { Phylum Actinobacteria }}{\text { Bifidobacterium spp. }}$} & \multirow{2}{*}{$\begin{array}{l}\text { Firmicutes/ } \\
\text { Bacteroidetes }\end{array}$} & \multirow{2}{*}{$\begin{array}{l}\text { Prevotella spp./ } \\
\text { Bacteroides spp. }\end{array}$} \\
\hline & & Total & Lactobacillus spp. & Enterococcus spp. & Clostridium leptum & Total & Prevotella spp. & Bacteroides spp. & & & \\
\hline \multirow[t]{4}{*}{ Blank } & 0 & $7.12 \pm 0.41^{\mathrm{a}}$ & $2.06 \pm 0.42^{\mathrm{a}}$ & $2.84 \pm 0.66^{\mathrm{a}}$ & $5.52 \pm 0.16^{\mathrm{a}}$ & $5.64 \pm 0.11^{b}$ & $4.11 \pm 0.88^{a}$ & $2.73 \pm 0.61^{b}$ & $3.96 \pm 0.34^{a}$ & $1.44 \pm 0.07^{\mathrm{a}, \mathrm{A}}$ & $1.57 \pm 0.44^{\mathrm{a}, \mathrm{A}}$ \\
\hline & 12 & $7.20 \pm 0.46^{\mathrm{a}, \mathrm{A}}$ & $2.34 \pm 0.24$ a, A & $3.52 \pm 0.78^{\mathrm{a}, \mathrm{A}}$ & $4.91 \pm 0.39^{\text {a }, A}$ & $6.60 \pm 0.18^{\mathrm{a}, \mathrm{A}}$ & $4.77 \pm 0.35^{\mathrm{a}, \mathrm{A}}$ & $5.08 \pm 0.46^{\mathrm{a}, \mathrm{A}}$ & $3.82 \pm 0.37^{\mathrm{a}, \mathrm{B}}$ & $1.13 \pm 0.02^{\mathrm{b}, \mathrm{A}}$ & $0.94 \pm 0.07^{\mathrm{a}, \mathrm{A}}$ \\
\hline & 24 & $7.64 \pm 0.23$ a, AB & $1.96 \pm 0.39^{\mathrm{a}, \mathrm{AB}}$ & $2.84 \pm 0.69^{\mathrm{a}, \mathrm{A}}$ & $4.89 \pm 0.14$ a, A & $5.42 \pm 0.23^{\mathrm{b}, \mathrm{A}}$ & $3.82 \pm 0.62^{\mathrm{a}, \mathrm{A}}$ & $2.63 \pm 0.37^{\mathrm{b}, \mathrm{A}}$ & $3.72 \pm 0.13^{\mathrm{a}, \mathrm{B}}$ & $1.44 \pm 0.06^{\mathrm{a}, \mathrm{A}}$ & $1.48 \pm 0.33^{\mathrm{a}, \mathrm{A}}$ \\
\hline & 48 & $7.56 \pm 0.28^{\text {a, } \mathrm{A}}$ & $1.54 \pm 0.31^{\mathrm{a}, \mathrm{AB}}$ & $2.79 \pm 0.61 \mathrm{a}, \mathrm{A}$ & $5.07 \pm 0.25$ a, A & $5.49 \pm 0.20^{\mathrm{b}, \mathrm{A}}$ & $3.57 \pm 0.14$ a, A & $2.54 \pm 0.11^{\mathrm{b}, \mathrm{AB}}$ & $3.37 \pm 0.13^{\mathrm{a}, \mathrm{A}}$ & $1.38 \pm 0.03^{\mathrm{a}, \mathrm{A}}$ & $1.41 \pm 0.05$ a, B \\
\hline \multirow[t]{3}{*}{ FOS } & 12 & $7.46 \pm 0.38^{\mathrm{a}, \mathrm{A}}$ & $2.41 \pm 0.24$ a, A & $4.39 \pm 0.66^{\mathrm{a}, \mathrm{A}}$ & $4.94 \pm 0.51^{\mathrm{a}, \mathrm{A}}$ & $6.68 \pm 0.37^{\mathrm{a}, \mathrm{A}}$ & $5.22 \pm 0.79^{\mathrm{a}, \mathrm{A}}$ & $4.71 \pm 0.17^{\mathrm{a}, \mathrm{A}}$ & $4.87 \pm 0.30^{\mathrm{a}, \mathrm{A}}$ & $1.12 \pm 0.06^{\mathrm{b}, \mathrm{A}}$ & $1.10 \pm 0.13^{\mathrm{b}, \mathrm{A}}$ \\
\hline & 24 & $7.12 \pm 0.18^{\mathrm{ab}, \mathrm{A}}$ & $2.49 \pm 0.40^{\mathrm{a}, \mathrm{A}}$ & $4.21 \pm 0.28^{\mathrm{a}, \mathrm{A}}$ & $4.71 \pm 0.23^{\mathrm{a}, \mathrm{AB}}$ & $4.94 \pm 0.49^{\mathrm{b}, \mathrm{A}}$ & $3.92 \pm 0.67^{\mathrm{a}, \mathrm{A}}$ & $2.41 \pm 0.39^{\mathrm{b}, \mathrm{A}}$ & $4.94 \pm 0.50^{\mathrm{a}, \mathrm{A}}$ & $1.50 \pm 0.13^{\mathrm{a}, \mathrm{A}}$ & $1.65 \pm 0.29$ ab, A \\
\hline & 48 & $6.44 \pm 0.52^{\mathrm{b}, \mathrm{B}}$ & $1.91 \pm 0.33^{\text {a, A }}$ & $3.16 \pm 0.39^{\mathrm{a}, \mathrm{A}}$ & $4.31 \pm 0.35^{\mathrm{a}, \mathrm{A}}$ & $4.52 \pm 0.37^{\mathrm{b}, \mathrm{A}}$ & $3.49 \pm 0.22$ a, A & $1.86 \pm 0.27^{\mathrm{b}, \mathrm{B}}$ & $3.92 \pm 0.57^{\text {a, } A}$ & $1.40 \pm 0.15 \mathrm{ab}, \mathrm{A}$ & $2.00 \pm 0.11$ a, A \\
\hline \multirow[t]{3}{*}{ POPP } & 12 & $7.36 \pm 0.44^{\mathrm{a}, \mathrm{A}}$ & $1.42 \pm 0.23^{\mathrm{a}, \mathrm{B}}$ & $3.61 \pm 0.77^{\mathrm{a}, \mathrm{A}}$ & $4.50 \pm 0.25$ a, A & $6.65 \pm 0.97^{\mathrm{a}, \mathrm{A}}$ & $4.70 \pm 0.17^{\mathrm{a}, \mathrm{A}}$ & $4.40 \pm 0.29^{\mathrm{a}, \mathrm{A}}$ & $3.50 \pm 0.41^{\mathrm{a}, \mathrm{B}}$ & $1.13 \pm 0.20^{\mathrm{a}, \mathrm{A}}$ & $1.07 \pm 0.10^{\mathrm{b}, \mathrm{A}}$ \\
\hline & 24 & $7.74 \pm 0.31 \mathrm{a}, \mathrm{A}$ & $1.01 \pm 0.18^{\mathrm{a}, \mathrm{B}}$ & $3.50 \pm 0.61^{\mathrm{a}, \mathrm{A}}$ & $4.41 \pm 0.38^{\text {a, } \mathrm{AB}}$ & $5.70 \pm 0.45^{\mathrm{a}, \mathrm{A}}$ & $4.31 \pm 0.16^{\mathrm{a}, \mathrm{A}}$ & $2.83 \pm 0.27^{\mathrm{b}, \mathrm{A}}$ & $3.39 \pm 0.38^{\text {a, } \mathrm{B}}$ & $1.36 \pm 0.10^{\text {a, } A}$ & $1.60 \pm 0.13^{\text {a, A }}$ \\
\hline & 48 & $7.70 \pm 0.19^{\text {a, } \mathrm{A}}$ & $0.83 \pm 0.15^{\mathrm{a}, \mathrm{B}}$ & $3.39 \pm 0.63^{\mathrm{a}, \mathrm{A}}$ & $4.50 \pm 0.20^{\mathrm{a}, \mathrm{A}}$ & $5.65 \pm 0.26^{\mathrm{a}, \mathrm{A}}$ & $4.13 \pm 0.37^{\mathrm{a}, \mathrm{A}}$ & $2.89 \pm 0.20^{\mathrm{b}, \mathrm{A}}$ & $3.15 \pm 0.35^{\mathrm{a}, \mathrm{A}}$ & $1.36 \pm 0.07^{\mathrm{a}, \mathrm{A}}$ & $1.43 \pm 0.08^{\text {а, в }}$ \\
\hline \multirow[t]{3}{*}{ LOPP } & 12 & $7.08 \pm 0.85^{\text {a, } \mathrm{A}}$ & $0.69 \pm 0.08^{\mathrm{a}, \mathrm{c}}$ & $2.90 \pm 0.70^{\mathrm{a}, \mathrm{A}}$ & $4.18 \pm 0.43^{\text {a, } A}$ & $7.01 \pm 1.01^{\mathrm{a}, \mathrm{A}}$ & $4.51 \pm 0.18^{\text {a, A }}$ & $4.80 \pm 0.27^{\text {a }, A}$ & $3.22 \pm 0.24$ a, в & $1.03 \pm 0.22^{\mathrm{b}, \mathrm{A}}$ & $0.96 \pm 0.06^{\mathrm{b}, \mathrm{A}}$ \\
\hline & 24 & $7.71 \pm 0.47$ a, $\mathrm{A}$ & $0.81 \pm 0.20^{\mathrm{a}, \mathrm{B}}$ & $3.52 \pm 0.60^{\mathrm{a}, \mathrm{A}}$ & $4.27 \pm 0.21$ a, B & $4.92 \pm 0.86^{\mathrm{a}, \mathrm{A}}$ & $3.45 \pm 0.25^{\mathrm{b}, \mathrm{A}}$ & $2.51 \pm 0.09^{\mathrm{b}, \mathrm{A}}$ & $3.57 \pm 0.30$ a, в & $1.60 \pm 0.23 \mathrm{a}, \mathrm{A}$ & $1.38 \pm 0.16^{\text {a, A }}$ \\
\hline & 48 & $7.52 \pm 0.62^{\mathrm{a}, \mathrm{A}}$ & $1.07 \pm 0.19^{\mathrm{a}, \mathrm{AB}}$ & $3.40 \pm 0.70^{\mathrm{a}, \mathrm{A}}$ & $4.46 \pm 0.31$ a, $\mathrm{A}$ & $5.01 \pm 0.83^{\mathrm{a}, \mathrm{A}}$ & $3.81 \pm 0.10^{\mathrm{b}, \mathrm{A}}$ & $2.33 \pm 0.41^{\mathrm{b}, \mathrm{AB}}$ & $3.21 \pm 0.49$ a, A & $1.52 \pm 0.16^{\mathrm{ab}, \mathrm{A}}$ & $1.59 \pm 0.33^{\text {a, } \mathrm{AB}}$ \\
\hline
\end{tabular}

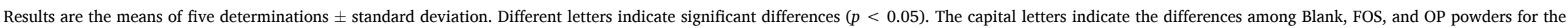
population of same microbial genus at the same time, and small letters indicate the differences for the same sample among time for the population of the same microbial genus. 

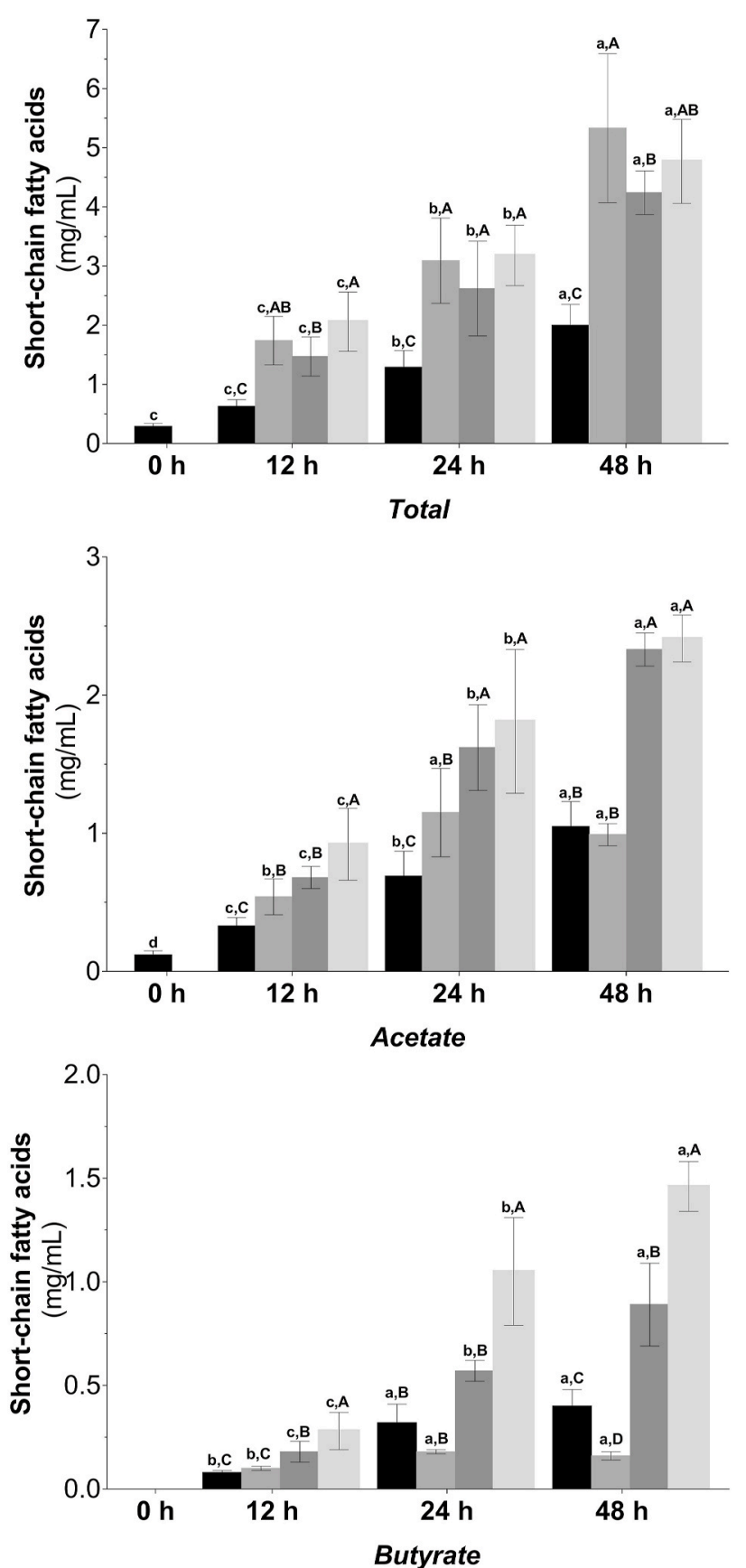

Butyrate
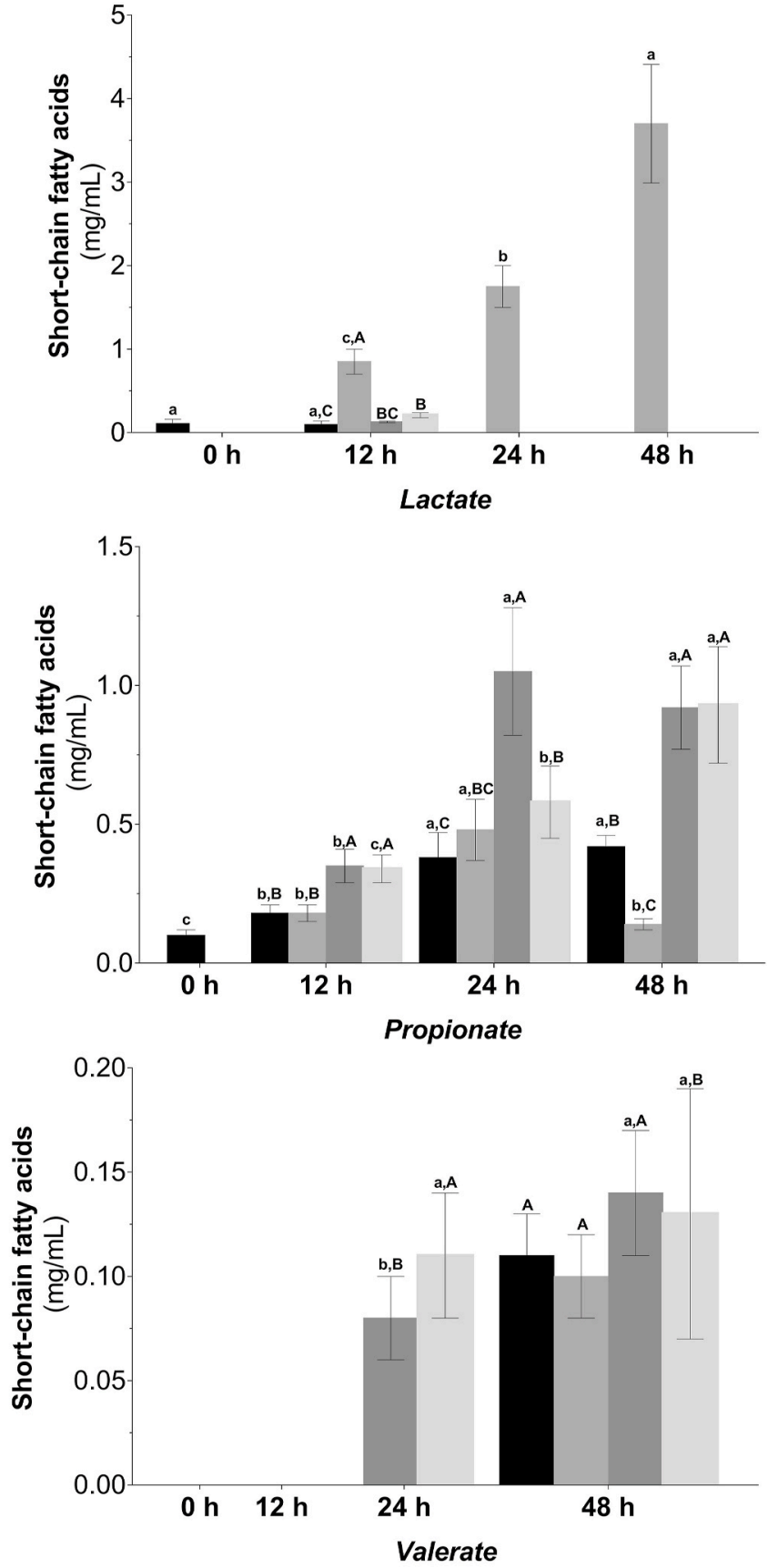

FOS

\section{LOPP}

Fig. 1. Concentrations of short-chain fatty acids (SCFAs) produced after 12, 24 and $48 \mathrm{~h}$ in vitro faecal fermentation of OP powders.

Antiadhesion ability $(\%)=\frac{\left(C F U_{\text {Control }}-C F U_{\text {Sample }}\right)}{C F U_{\text {Control }}} \times 100$

Where $C F U_{\text {Control }}$ was the average for control samples, and $C F U_{\text {Sample }}$ was the average for treated samples.

\subsection{Statistical analyses}

The statistical analyses were carried out using R software. The significance of the differences between samples after in vitro colonic fermentation was determined by one-way analysis of variance (ANOVA) or Kruskal-Wallis according to the normality of data distribution (Shapiro-Wilk test) and homogeneity of variances (Levene's test).Test multiple comparisons were made at those statistically significant variables using the Tukey's posthoc test or Dunn's method at the $p<0.05$ significance level.

Supervised cluster analysis (Partial Least Squares Discriminant Analysis (PLS-DA)) and hierarchical clustering analysis (HCA) were applied to evaluate the metabolite patterns of OP powders detected (relative intensity) as a function of time using MetaboAnalyst 3.0 (http://www.metaboanalyst.ca/) on log-transformed data after autoscaling (mean-centred and divided by the standard deviation of each variable). The HCA was applied with Euclidean distance measure and Ward clustering algorithm. 


\section{Results and discussion}

\subsection{Changes in faecal microbial communities during in vitro fermentation}

The real-time PCR investigation on the microbial groups' Firmicutes, Lactobacillus spp., Enterococcus spp., Clostridium leptum, Bacteroidetes, Bacteroides spp., Prevotella spp., and Bifidobacterium spp. were used to assess the OP powders effect on gut microbiota. For comparison, FOS was used as a positive control, i.e. compound with a prebiotic effect on the gut microbiota. As seen in Table 1, the most significant effects of OP powders were verified in Firmicutes and Bacteroidetes groups $(p<0.05)$. In healthy adults, the Gram-positive Firmicutes and the Gram-negative Bacteroidetes are the main phyla in the human gut microbiome (Abenavoli et al., 2019). During the time of fermentation, the highest amounts of Firmicutes and Bacteroidetes were verified after $12 \mathrm{~h}$ of fermentation of FOS and OP powders. After 24 and $48 \mathrm{~h}$, OP powders showed that they could maintain the growth of these two major phyla without decreasing their amounts significantly. On the other hand, FOS influenced more positively the amount of Firmicutes and Bacteroidetes until $12 \mathrm{~h}$ of fermentation, but cell numbers decreased significantly after that $(p>0.05)$. These decreases could be related to the fact that the in vitro faecal fermentation of this work was performed without $\mathrm{pH}$ control. OP powders seemed to have a more prolongated positive effect on Firmicutes and Bacteroidetes than FOS. Indeed, POPP increased significantly $(p<0.05)$ the amount of Firmicutes compared to the FOS, principally after the $48 \mathrm{~h}$ of fermentation. This result was expected due to the higher amount of dietary fibre of POPP. Previous studies showed that diets low in fat and high in dietary fibre were associated with higher Firmicutes amount (Simpson \& Campbell, 2015). Regarding Bacteroidetes, OP powders and FOS had a positive and similar effect on this group $(p<$ 0.05 ) after 12, 24 and $48 \mathrm{~h}$ of in vitro colon fermentation.

It is known that more important than the stimulation of the amount of Firmicutes and Bacteroidetes, it is to maintain the relative abundance of these two prominent phyla (Simpson \& Campbell, 2015). Commonly, healthy individuals display a nearly 1:1 ratio of Firmicutes to Bacteroidetes (F/B) (Cockburn \& Koropatkin, 2016) and its increase (e.g., to $20: 1$ ) or decrease have been associated with obesity and weight loss, respectively (Koliada et al., 2017). OP powders and FOS maintained the ratio of F/B stable and near to one without significant differences.

Another important ratio is the Prevotella spp. to Bacteroides spp. (P/B) ratio. Bacteroides spp. and Prevotella spp. belong to the Bacteroidetes phylum and are among the most abundant anaerobes in the human colon (Flint \& Duncan, 2014). If higher levels of Bacteroides spp. are related with a superior intake of fat and protein, increased levels of Prevotella spp. are correlated with high carbohydrates and fibre intake (Jiao et al., 2019; Kovatcheva-Datchary et al., 2015). An increasing number of studies have suggested that Prevotella spp. is a microbial group associated with beneficial gut microbiota (Rui et al., 2019), particularly in the improvement of glucose metabolism (Kovatcheva-Datchary et al., 2015). On the other hand, Bacteroides spp. had demonstrated potential health benefits for hosts by suppressing intestinal inflammatory responses and promoting intestinal homeostasis (Rui et al., 2019). However, a higher P/B ratio protects against Bacteroides spp. -induced glucose intolerance (Kovatcheva-Datchary et al., 2015). FOS and OP powders increased $\mathrm{P} / \mathrm{B}$ ratio through fermentation. LOPP and FOS improved $\mathrm{P} / \mathrm{B}$ ratio until $48 \mathrm{~h}$ of fermentation without significant differences. Instead, POPP had a similar effect to FOS and LOPP until $24 \mathrm{~h}$. The amount of Prevotella spp. between OP powders was very similar throughout fermentation. The higher amount of Prevotella spp. throughout fermentation could be explained by the high amount of dietary fibre and soluble sugars (mainly the polyol mannitol, which is considered a prebiotic substance) on POPP and LOPP (Supplementary material A3), respectively (Jiao et al., 2019; Kovatcheva-Datchary et al., 2015). On the other hand, the higher amount of Bacteroides spp. after 24 and $48 \mathrm{~h}$ of POPP fermentation could be related to its higher amount of fat (Supplementary material A3).
Regarding the other bacteria of Firmicutes phylum evaluated, OP powders did not negatively affect the Lactobacillus spp., Clostridium leptum and Enterococcus spp. genus compared to the blank. However, FOS exhibited a significant positive effect on the growth of Lactobacillus spp. group compared to OP powders $(p<0.05)$. In the Actinobacteria phylum, the same behaviour with FOS and OP powders was verified when compared to the Bifidobacterium spp. group, associated with health positive effects.

Regarding the time of fermentation, OP powders were fermented more slowly than FOS. Most in vitro fermentation studies suggest that less soluble substrates (e.g., insoluble arabinoxylan, cellulose) and with longer chain lengths are fermented more slowly. POPP, as reported in our previous work, was mainly a source of insoluble cellulose and arabinoxylan (Supplementary material A3), which explain its slower fermentation rates by microbiota. On the other hand, LOPP is mostly a source of mannitol and phenolics, which are metabolised by gut microbiota, but less than oligosaccharides such as FOS and inulin. Mannitol effect as potential prebiotic was reported upon its use as a substrate on the acrylic pathway, which is observed only in some Clostridium spp. and Prevotella spp., such as C. propionicum and P. ruminicola (Maekawa et al., 2009). In turn, as shown by Parkar et al. (2013), in order to increase the gut microbiota in the same degree than oligosaccharides, polyphenols needed to be supplied at higher concentrations (at least ten times more). Nevertheless, the slow fermentation of OP powders could be an advantage in terms of health benefits, e.g. to avoid the production of gases that can result in discomfort, such as bloating and flatulence, and will also allow the production of SCFAs throughout the colon preventing colon cancer, which mainly occurs in the distal colon (Seong et al., 2019).

Until now, the influence of OP on the composition of human gut microbiota was only assessed by incorporating the OP into a biscuit formulation (Conterno et al., 2019). In the Conterno et al. (2019) study, the potential of an olive pomace-enriched biscuit formulation delivering $17.1 \pm 4.01 \mathrm{mg} / 100 \mathrm{~g}$ of hydroxytyrosol and its derivatives to modulate the composition and metabolic activity of the human gut microbiota was measured by a double-blind, controlled parallel dietary intervention during 8 weeks. The 16S rRNA metagenomics analysis of dominant bacterial phyla revealed a change in relative abundance at the genus level for Bifidobacterium spp., Ruminococcus spp. and Lactobacillus spp., while quantitative analysis using fluorescent in situ hybridisation coupled with flow cytometry did not confirm these Results. Besides, qPCR showed a slight increase in Bifidobacterium spp. group.

As in the study of Conterno et al. (2019), the analysis of the 16S rRNA gene results (Table 1) allowed to validate that OP powders did not impact negatively on the diversity of the faecal microbiota.

\subsection{Short-chain fatty acids production during in vitro faecal fermentation}

The changes in the concentration of SCFAs after the fermentation of OP powders $(2 \%)$ and FOS $(2 \%)$ with human faeces in basal media analysed by HPLC are presented in Fig. 1.

Results are the means of five determinations \pm standard deviation. Different letters indicate significant differences $(p<0.05)$. The capital letters indicate the differences among Blank, FOS, and OP powders for short-chain fatty acids concentration at the same time, and small letters indicate the differences for the same sample among time for short-chain fatty acids concentration.

SCFAs are volatile fatty acids produced by the gut microbiota in the colon as fermentation products from food components that are unabsorbed/undigested in the small intestine, such as acetate, propionate, butyrate and valerate (Ríos-Covián et al., 2016a). These SCFAs can be produced during growth phases (initial $v s$ late), be present in medium composition (presence and absence of amino acids) and be produced by metabolic cross-feeding (e.g. consumption of lactate or formate to produce acetate) (Seong et al., 2019). Butyrate and propionate derive exclusively from bacterial metabolism, but acetate could also have an 

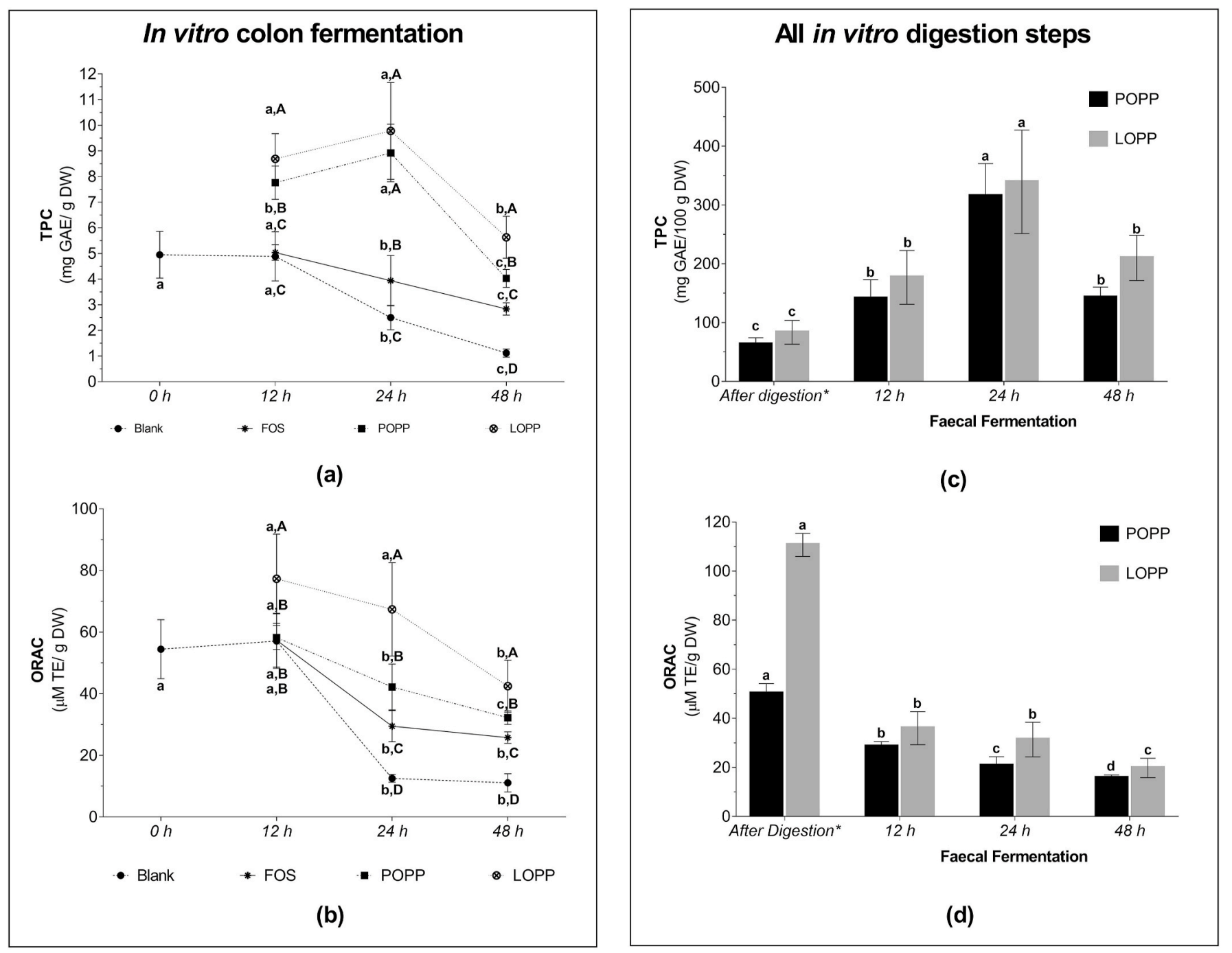

Fig. 2. Total phenolic content (TPC), expressed as gallic acid equivalents (GAE), and antioxidant capacity (ORAC radical scavenging), expressed as trolox equivalents (TE) after 12, 24 and $48 \mathrm{~h}$ of the in vitro faecal fermentation of olive pomace (OP) powders. (a) OP powders TPC (mg GAE/100 $\mathrm{g}$ DW fermented sample) during the faecal fermentation in comparison to FOS and Blank. (b) OP powders ORAC ( $\mu \mathrm{mol} \mathrm{L}{ }^{-1} \mathrm{TE} / \mathrm{g} \mathrm{DW}$ fermented sample) during the faecal fermentation in comparison to FOS and Blank. (c) OP powders TPC (mg GAE/100 g DW sample) in the digested OP powders and during 8, 24 and $48 \mathrm{~h}$ of the in vitro faecal fermentation process. (d) OP powders ORAC ( $\mu \mathrm{mol} \mathrm{L}^{-1} \mathrm{TE} / \mathrm{g}$ DW sample) in the digested OP powders and during 8,24 and $48 \mathrm{~h}$ of the in vitro faecal fermentation process.

endogenous origin (Pouteau et al., 1998; Tabernero \& Gómez de Cedrón, 2017).

The OP powders and FOS showed to enhance the production of total SCFAs substantially without significant differences between each other. However, different production profiles of SCFAs were detected for FOS and OP powders. In FOS fermentation, the main metabolite produced during the whole fermentation was lactate. On the other hand, lactate production was nearly null during OP powders faecal fermentation. The low stimulation of Lactobacillus spp. and Bifidobacterium spp. group by OP powders explained this limited production of lactate (Dominika et al., 2011), validated above with 16S rRNA gene analysis.

The OP powders enhanced the production of the acetate, propionate and butyrate principally in a ratio of 3:1:1, as reported in previous works (Cummings, 1981; Scott et al., 2013; Topping \& Clifton, 2001). The SCFA production stimulated by OP powders and FOS increased throughout fermentation time. Nevertheless, only the fermentation of OP powders showed an increase in the amount of acetate, propionate and butyrate that could be considered significantly different from the blank sample $(p>0.05)$. This higher production of SCFAS was reported in other in vitro batch fermentation investigations using human faecal inocula with slow fermentation rate like OP powders (Wang et al.,
2019).

Comparing the OP powders, POPP led to a higher rise of propionate production than LOPP after $24 \mathrm{~h}$ of faecal fermentation. This high amount of propionate resulted from the higher abundance of Bacteroidetes detected in POPP when compared to LOPP after 24 and $48 \mathrm{~h}$. Bacteroidetes, as members of the polysaccharide-degrading consortia, contribute to the release of energy from DF, which is the main component of POPP and consequent propionate formation (Flint \& Duncan, 2014; Koh et al., 2016). Bacteroidetes are likely to be the main contributors to propionate production in the colon (Flint \& Duncan, 2014).

Compared to POPP, only the amount of butyrate was significantly higher in LOPP than in POPP after 24 and $48 \mathrm{~h}$ of fermentation $(p<$ 0.05). The main butyrate-producing groups belong to Firmicutes phylum (De Vuyst \& Leroy, 2011; Parkar et al., 2013), more specifically Coprococcus comes, C. eutactus, C. catus, E. rectale, E. hallii, F. prausnitzii, Anaerostipes spp., Roseburia spp (Koh et al., 2016). These genera were not measured in the present work, and no significant differences were observed in phylum Firmicutes between LOPP and POPP. However, a typical cross-feeding effect could occur among the genus of intestinal bacteria enumerated (except $C$. comes, $C$. eutectic) using acetate to synthesise butyrate via the butyryl-CoA: acetate CoA-transferase route (De 
Vuyst \& Leroy, 2011; Koh et al., 2016), which could explain the higher amount of butyrate in LOPP fermentation. The LOPP rich composition in sugar and formic acid (Supplementary material A3) could enhance the production of acetate by enteric bacteria fermentation or by acetogenic bacteria fermentation via Wood-Ljungdahl pathway, respectively (Seong et al., 2019). In an acetate-rich colon ecosystem, previous studies reported that butyryl-CoA: acetate CoA transferase activity has been more common among butyrate-producing groups (De Vuyst \& Leroy, 2011; Louis et al., 2004, 2007). This makes LOPP acetate a key intermediate for colon butyrate. On the other hand, as reported by Maekawa et al. (2009), mannitol present at substantial amount in LOPP (Supplementary material A3), was associated to the stimulation of the lactate-utilising butyrate producers and propionate producers. Other reason for the higher increase of butyrate in LOPP fermentation could be linked to its higher polyphenols content. Caffeic acid and its derivative caffeoyl-6'-secologanoside were detected in higher amounts in LOPP undigested fraction (Supplementary material A3), and its metabolisation might be responsible for the enhanced production of butyrate in the fermentation of these OP powders. In previous studies, at concentrations of 10 and $100 \mathrm{mg} \mathrm{mL}^{-1}$, the caffeic acid standard exhibited the highest increase in butyrate production after $24 \mathrm{~h}$ of faecal fermentation when compared to other phenolics (chlorogenic acid, caffeic acid, rutin and quercetin) and inulin (Parkar et al., 2013).

The common cross-feeding effect among intestinal bacteria of production of acetate, propionate or butyrate as the final metabolite using the lactate as substrate (Koh et al., 2016; Seong et al., 2019) was not evident during FOS fermentation. Indeed, lactate was accumulated throughout the fermentation time, and its utilisation was not verified, once the other SCFAs concentrations were maintained or decreased after $24 \mathrm{~h}$. So, the prevention of the accumulation of lactate in order to stabilise the intestinal environment was not verified in FOS fermentation, which could result in further acidosis that could be related with certain gut disorders or dietary intakes and lead to adverse consequences (Kowlgi \& Chhabra, 2015). However, the low pH value of the faecal fermentation (the in vitro faecal fermentation experiment of this work performed without $\mathrm{pH}$ control) of FOS could be responsible for the accumulation of lactate (Belenguer et al., 2007).

The SCFAs as metabolites of gut microbiota are distributed throughout the body, having diverse functions such as signalling molecules and/or energy substrates. In the colon, SCFAs could inhibit pathogenic microorganisms, increase the absorption of some nutrients and seem to play an essential role in the maintenance of the gut barrier function (Ríos-Covián et al., 2016b). During its intestinal absorption, butyrate may be metabolised (energy source) by colonocytes. At the same time, propionate may be transported to the liver where it has a role in gluconeogenesis, and acetate enters the systemic circulation and is used in lipogenesis (Scott et al., 2013). SCFAs might play a vital role in the metabolic pathways of several organs, modulating different processes including cell proliferation and differentiation, hormones secretion (e.g., leptin and peptide YY) and activation of immune/inflammatory responses (Gullon et al., 2015; Koh et al., 2016). Many biological effects seem to be mediated by SCFAs, namely (1) acetate and propionate might affect satiety and intestinal transit; (2) butyrate could exert anti-inflammatory effects; (3) propionate could lead to satiety and decreased hepatic glucose production; (4) small amounts of SCFAs (mostly acetate and possibly propionate) reach the circulation and can also directly affect the adipose tissue, brain, and liver, inducing overall beneficial metabolic effects and (5) SCFAs can also reduce inflammation and tumorigenesis (Koh et al., 2016; Ríos-Covián et al., 2016b). The role of SCFAs in the prevention and treatment of several diseases such as metabolic syndrome, bowel disorders and cancer has also been reported in several studies (Gullon et al., 2015). Still, excessive SCFAs concentrations might induce adverse effects on gastrointestinal and colonic motility and sensitivity in certain diseases such as inflammatory bowel disease and gastro-oesophageal reflux disease, and the conclusive proof is not available for many of the health claims made for SCFAs (Gullon et al., 2015; Ríos-Covián et al., 2016b).

Despite the higher total SCFAs production by FOS, OP powders exhibited a profile of SCFAs with a higher concentration of acetate, propionate and butyrate throughout the fermentation time. These SCFAs could exert interesting, beneficial health properties not only in the colon and gut microbiota but also in other organs. So, OP powders could be considered prebiotics as inducers of the SCFAs production activity by gut microorganisms.

\subsection{Phenolic compounds throughout in vitro faecal fermentation}

\subsubsection{Total phenolic compounds and antioxidant activity}

The total phenolic content (TPC), as assayed according to the FolinCiocalteu method, along with in vitro antioxidant capacity (ORAC radical scavenging), was investigated to support the following evaluation of phenolic profile through LC-ESI-UHR-QqTOF-MS. Fig. 2 displays the TPC and the in vitro antioxidant capacity (ORAC radical scavenging) during in vitro faecal fermentation process $(8,24$, and $48 \mathrm{~h}$ ) in comparison to FOS and blank, but also the TPC and ORAC of the digested OP powder previously evaluated and throughout the in vitro faecal fermentation process $(8,24$, and $48 \mathrm{~h})$ expressed by DW of OP powder. Comparing TPC Results of OP powders with FOS, OP powders showed significant higher TPC values $(p<0.05)$ due to their richness in polyphenolic compounds. Indeed, TPC values were constant during FOS faecal fermentation time (3-5 mg GAE/g DW), which corroborates that FOS as polysaccharide did not contain polyphenols to liberate after microbial fermentation.

In vitro faecal fermentation Results are the means of five determinations \pm standard deviation. *Samples analysed in previous works. Different letters indicate significant differences $(p<0.05)$. The capital letters indicate the differences among Blank, FOS, and OP powders at the same time, and small letters indicate the differences for the same sample among the digestion phase.

Concerning OP powders, LOPP and POPP revealed similar TPC values after 12 and $24 \mathrm{~h}$ of faecal fermentation. Indeed, both fermented OP powders exhibited the highest TPC after $24 \mathrm{~h}$ of in vitro colonic fermentation (POPP: $8.92 \pm 1.12 \mathrm{mg} \mathrm{GAE} / \mathrm{g}$ DW; LOPP: $9.78 \pm 1.89 \mathrm{mg}$ $\mathrm{GAE} / \mathrm{g}$ DW). Nevertheless, after $48 \mathrm{~h}$ of fermentation both OP powders decreased their TPC values, even though LOPP kept a significantly higher TPC value than POPP $(p<0.05)$, with values of $5.63 \pm 0.82 \mathrm{mg}$ $\mathrm{GAE} / \mathrm{g}$ DW and $4.03 \pm 0.35 \mathrm{mg} \mathrm{GAE} / \mathrm{g}$ DW, respectively. The highest TPC values of LOPP throughout in vitro colon fermentation might be linked to its higher polyphenol richness (Supplementary material A3). As LOPP comprise more polyphenols than POPP, it could originate higher amounts of phenolic metabolites during the faecal fermentation process as reviewed by Duda-Chodak et al. (2015). A similar increase in TPC after $24 \mathrm{~h}$ of fermentation was reported for a goji berries mix (Rocchetti et al., 2018) and black mulberry (Bao et al., 2019). However, Bao et al. (2019) also described that TPC of black mulberry decreased from 24 to $48 \mathrm{~h}$ of fermentation time as shown to happen for LOPP, while TPC of white mulberry decreased until $48 \mathrm{~h}$ of fermentation time, as observed for POPP.

Considering the TPC results of the previous works regarding the digested OP powders, a significant increase of phenolic compounds occurred after faecal fermentation for both OP powders (Fig. 2 c). An increase in TPC value from $93 \%$ to $255 \%$ was exhibited from digested to fermented OP powders. Similar levels of increase were reported for black mulberry (Bao et al., 2019) after 12, 24 and $48 \mathrm{~h}$. This effect has been associated with gut microbiota being capable of transforming larger phenolic molecules to smaller ones during colonic fermentation (Rocchetti et al., 2018) using the free and bound phenolic fraction of OP powders (Rocchetti et al., 2019). The higher amount of bound phenolics of POPP could explain the significant increase of TPC just after $12 \mathrm{~h}$ of fermentation $(p<0.05)$ when compared to digested POPP. In the case of LOPP, only after $24 \mathrm{~h}$ of fermentation, the TPC value was significantly 
Table 2

Detection of polyphenols and its metabolites after 12, 24 and $48 \mathrm{~h}$ of the in vitro faecal fermentation of the OP powders.

\begin{tabular}{|c|c|c|c|c|c|c|c|c|c|c|c|c|c|c|}
\hline & \multirow[t]{3}{*}{ Compound } & \multirow{3}{*}{$\begin{array}{l}\text { Molecular } \\
\text { formula }\end{array}$} & \multirow{3}{*}{$\begin{array}{l}\mathrm{RT} \\
(\mathrm{min})\end{array}$} & \multirow{3}{*}{$\begin{array}{l}\mathrm{m} / \mathrm{z} \\
\text { calcd }\end{array}$} & \multirow{3}{*}{$\begin{array}{l}\mathrm{m} / \mathrm{z} \\
\text { exptl }\end{array}$} & \multirow{3}{*}{$\begin{array}{l}\text { Err } \\
{[\mathrm{mDa}]}\end{array}$} & \multirow[t]{3}{*}{ mSigma } & \multirow{3}{*}{$\begin{array}{l}\text { Major } \\
\text { fragments ESI } \\
\text { negative MS/ } \\
\text { MS ions }\end{array}$} & \multicolumn{6}{|c|}{ In vitro faecal fermentation time (h) } \\
\hline & & & & & & & & & \multicolumn{3}{|c|}{ POPP } & \multicolumn{3}{|c|}{ LOPP } \\
\hline & & & & & & & & & 12 & 24 & 48 & 12 & 24 & 48 \\
\hline M1 & Oxidised hydroxytyrosol $^{\mathrm{b}}$ & $\mathrm{C}_{6} \mathrm{H}_{12} \mathrm{O}_{6}$ & 1.5 & 179.0561 & 179.0511 & 0.3 & 12.2 & $\begin{array}{l}179.0563 \\
161.0457 \\
89.0242 \\
75.0086\end{array}$ & $\mathrm{D}$ & $\mathrm{D}$ & $\mathrm{D}$ & $\mathrm{D}$ & $\mathrm{D}$ & $\mathrm{D}$ \\
\hline M2 & Hydroxytyrosol glucoside ${ }^{b}$ & $\mathrm{C}_{14} \mathrm{H}_{20} \mathrm{O}_{8}$ & 7.1 & 315.1088 & 315.1085 & 0.0 & 9.1 & $\begin{array}{l}315.1092 \\
153.0556 \\
123.0451\end{array}$ & $\mathrm{D}$ & $\mathrm{D}$ & $\mathrm{D}$ & $\mathrm{D}$ & $\mathrm{D}$ & $\mathrm{D}$ \\
\hline M3 & $\begin{array}{l}\text { Hydrated product of the } \\
\text { dialdehydic form of } \\
\text { decarboxymethyl-elenolic acid }\end{array}$ & $\mathrm{C}_{9} \mathrm{H}_{14} \mathrm{O}_{5}$ & 7.2 & 201.077 & 201.0768 & 0.1 & 6.5 & $\begin{array}{l}201.0405 \\
153.0553 \\
123.0449 \\
95.0502\end{array}$ & $\mathrm{D}$ & $\mathrm{D}$ & $\mathrm{D}$ & $\mathrm{D}$ & $\mathrm{D}$ & $\mathrm{D}$ \\
\hline M4 & 3,4 - Dihydroxybenzoic acid ${ }^{c}$ & $\mathrm{C}_{7} \mathrm{H}_{6} \mathrm{O}_{4}$ & 7.3 & 153.0193 & 153.0198 & 0.3 & 9.2 & $\begin{array}{l}153.0198 \\
109.0295\end{array}$ & $\mathrm{D}$ & $\mathrm{D}$ & ND & $\mathrm{D}$ & $\mathrm{D}$ & $\mathrm{D}$ \\
\hline M5 & Vanillyl alcohol $^{\mathrm{c}}$ & $\mathrm{C}_{8} \mathrm{H}_{10} \mathrm{O}_{3}$ & 7.4 & 153.0557 & 153.0493 & 0.2 & 5.2 & $\begin{array}{l}153.0557 \\
123.0447\end{array}$ & ND & ND & $\mathrm{D}$ & ND & ND & ND \\
\hline M6 & Hydroxytyrosol ${ }^{\mathrm{a}}$ & $\mathrm{C}_{8} \mathrm{H}_{10} \mathrm{O}_{3}$ & 7.5 & 153.0556 & 153.0557 & 0.1 & 5.7 & $\begin{array}{l}153.0452 \\
123.0457\end{array}$ & $\mathrm{D}$ & $\mathrm{D}$ & $\mathrm{D}$ & $\mathrm{D}$ & $\mathrm{D}$ & $\mathrm{D}$ \\
\hline M7 & Oleoside derivative isomer ${ }^{\mathrm{b}}$ & $\mathrm{C}_{17} \mathrm{H}_{28} \mathrm{O}_{11}$ & 7.7 & 407.1557 & 407.1559 & -0.5 & 11.7 & $\begin{array}{l}151.0760 \\
119.0346\end{array}$ & $\mathrm{D}$ & $\mathrm{D}$ & $\mathrm{D}$ & $\mathrm{D}$ & $\mathrm{D}$ & $\mathrm{D}$ \\
\hline M8 & $\begin{array}{l}\text { Decarboxylated form of } \\
\text { hydroxy-elenolic acid }{ }^{b}\end{array}$ & $\mathrm{C}_{10} \mathrm{H}_{14} \mathrm{O}_{5}$ & 7.9 & 213.0765 & 213.0768 & 0.1 & 5.6 & $\begin{array}{l}213.0920 \\
137.0601 \\
121.0665 \\
111.0085\end{array}$ & $\mathrm{D}$ & $\mathrm{D}$ & $\mathrm{D}$ & $\mathrm{D}$ & $\mathrm{D}$ & $\mathrm{D}$ \\
\hline M9 & $\begin{array}{l}\text { 3-(3,4-Dihydroxyphenyl)- } \\
\text { propionic acid }^{\mathrm{d}}\end{array}$ & $\mathrm{C}_{9} \mathrm{H}_{10} \mathrm{O}_{4}$ & 8.0 & 181.0506 & 181.0452 & 0.0 & 5.4 & $\begin{array}{l}181.0507 \\
163.0397 \\
135.0447\end{array}$ & $\mathrm{D}$ & $\mathrm{D}$ & ND & $\mathrm{D}$ & $\mathrm{D}$ & $\mathrm{D}$ \\
\hline M10 & Tyrosol glucoside $^{c}$ & $\mathrm{C}_{14} \mathrm{H}_{20} \mathrm{O}_{7}$ & 8.1 & 299.1139 & 299.1136 & -0.3 & 3.2 & $\begin{array}{l}119.0505 \\
137.0244 \\
135.0299\end{array}$ & $\mathrm{D}$ & $\mathrm{D}$ & $\mathrm{D}$ & $\mathrm{D}$ & $\mathrm{D}$ & $\mathrm{D}$ \\
\hline M11 & $\begin{array}{l}\text { Hydroxylated product of the } \\
\text { dialdehydic form of } \\
\text { decarboxymethyl-elenolic acid }{ }^{\mathrm{b}}\end{array}$ & $\mathrm{C}_{9} \mathrm{H}_{12} \mathrm{O}_{5}$ & 8.2 & 199.0612 & 199.0564 & 0.0 & 9.5 & $\begin{array}{l}199.0616 \\
155.0709 \\
111.0812\end{array}$ & $\mathrm{D}$ & $\mathrm{D}$ & $\mathrm{D}$ & $\mathrm{D}$ & $\mathrm{D}$ & $\mathrm{D}$ \\
\hline M12 & Oleoside $^{\mathrm{b}}$ & $\mathrm{C}_{16} \mathrm{H}_{22} \mathrm{O}_{11}$ & 8.4 & 389.1093 & 389.1089 & -0.4 & 4.3 & $\begin{array}{l}389.1092 \\
183.0664 \\
165.0556 \\
121.0654\end{array}$ & $\mathrm{D}$ & $\mathrm{D}$ & $\mathrm{D}$ & $\mathrm{D}$ & $\mathrm{D}$ & $\mathrm{D}$ \\
\hline M13 & p-Coumaroyl-D-glucose ${ }^{c}$ & $\mathrm{C}_{15} \mathrm{H}_{18} \mathrm{O}_{8}$ & 8.7 & 325.0925 & 325.0929 & 0.4 & 0.9 & $\begin{array}{l}326.0976 \\
163.0402 \\
119.0501\end{array}$ & $\mathrm{D}$ & $\mathrm{D}$ & $\mathrm{D}$ & $\mathrm{D}$ & $\mathrm{D}$ & $\mathrm{D}$ \\
\hline M14 & $\begin{array}{l}\text { Oleuropein aglycone derivative } \\
\mathrm{c}\end{array}$ & $\mathrm{C}_{16} \mathrm{H}_{26} \mathrm{O}_{10}$ & 9.6 & 377.1453 & 377.1353 & 0.3 & 9.4 & $\begin{array}{l}377.1452 \\
197.0825 \\
153.0918\end{array}$ & $\mathrm{D}$ & $\mathrm{D}$ & $\mathrm{D}$ & $\mathrm{D}$ & $\mathrm{D}$ & $\mathrm{D}$ \\
\hline M15 & Tyrosol $^{\mathrm{a}}$ & $\mathrm{C}_{8} \mathrm{H}_{10} \mathrm{O}_{2}$ & 9.8 & 137.0608 & 137.0608 & 0.5 & 4.5 & $\begin{array}{l}111.0084 \\
95.0510\end{array}$ & $\mathrm{D}$ & $\mathrm{D}$ & $\mathrm{D}$ & $\mathrm{D}$ & $\mathrm{D}$ & $\mathrm{D}$ \\
\hline M16 & $\begin{array}{l}\text { Aldehydic form of } \\
\text { decarboxymethyl elenolic acid }\end{array}$ & $\mathrm{C}_{10} \mathrm{H}_{16} \mathrm{O}_{5}$ & 10.8 & 215.0925 & 215.0873 & 0.1 & 7.6 & $\begin{array}{l}215.0925 \\
153.0918 \\
171.1026\end{array}$ & $\mathrm{D}$ & $\mathrm{D}$ & $\mathrm{D}$ & $\mathrm{D}$ & $\mathrm{D}$ & $\mathrm{D}$ \\
\hline M17 & Elenolic acid $^{\mathrm{b}}$ & $\mathrm{C}_{11} \mathrm{H}_{14} \mathrm{O}_{6}$ & 12.5 & 241.0720 & 241.0718 & -0.2 & 0.5 & $\begin{array}{l}241.0737 \\
139.0035 \\
127.0398 \\
111.0086 \\
95.0551\end{array}$ & $\mathrm{D}$ & $\mathrm{D}$ & $\mathrm{D}$ & $\mathrm{D}$ & $\mathrm{D}$ & $\mathrm{D}$ \\
\hline M18 & $\begin{array}{l}3 \text { - (4-Hydroxyphenyl) propionic } \\
\text { acid }^{\mathrm{d}}\end{array}$ & $\mathrm{C}_{9} \mathrm{H}_{10} \mathrm{O}_{3}$ & 12.6 & 165.0557 & 165.0505 & 0.0 & 7.9 & $\begin{array}{l}165.0557 \\
147.0451 \\
119.0499 \\
103.0552\end{array}$ & $\mathrm{D}$ & $\mathrm{D}$ & $\mathrm{D}$ & $\mathrm{D}$ & $\mathrm{D}$ & $\mathrm{D}$ \\
\hline M19 & $\begin{array}{l}\text { 3-Hydroxyphenilpropionic acid } \\
\text { d }\end{array}$ & $\mathrm{C}_{9} \mathrm{H}_{10} \mathrm{O}_{3}$ & 12.7 & 165.0557 & 165.0489 & 0.1 & 7.0 & $\begin{array}{l}165.0556 \\
121.0655 \\
121.0294 \\
106.0423\end{array}$ & $\mathrm{D}$ & $\mathrm{D}$ & $\mathrm{D}$ & $\mathrm{D}$ & $\mathrm{D}$ & $\mathrm{D}$ \\
\hline M20 & $\begin{array}{l}3 \text { - hydroxy-4- } \\
\text { methoxyphenyllactic acid }{ }^{d}\end{array}$ & $\mathrm{C}_{10} \mathrm{H}_{12} \mathrm{O}_{5}$ & 13.0 & 211.0612 & 211.0560 & 0.5 & 4.0 & $\begin{array}{l}211.0612 \\
165.0569 \\
123.0812\end{array}$ & $\mathrm{D}$ & $\mathrm{D}$ & $\mathrm{D}$ & $\mathrm{D}$ & $\mathrm{D}$ & $\mathrm{D}$ \\
\hline M21 & Homovanilic alcohol ${ }^{\mathrm{d}}$ & $\mathrm{C}_{9} \mathrm{H}_{12} \mathrm{O}_{3}$ & 13.2 & 167.0714 & 167.0655 & 0.3 & 11.1 & $\begin{array}{l}166.0585 \\
139.0412 \\
136.9341 \\
109.0273 \\
121.0517\end{array}$ & $\mathrm{D}$ & $\mathrm{D}$ & $\mathrm{D}$ & ND & $\mathrm{D}$ & $\mathrm{D}$ \\
\hline M22 & Homovanillic acid $^{\mathrm{d}}$ & $\mathrm{C}_{9} \mathrm{H}_{10} \mathrm{O}_{4}$ & 13.7 & 181.0506 & 181.0464 & 0.8 & 8.7 & $\begin{array}{l}181.0486 \\
137.0611\end{array}$ & $\mathrm{D}$ & $\mathrm{D}$ & $\mathrm{D}$ & $\mathrm{D}$ & $\mathrm{D}$ & $\mathrm{D}$ \\
\hline
\end{tabular}


Table 2 (continued)

\begin{tabular}{|c|c|c|c|c|c|c|c|c|c|c|c|c|c|c|}
\hline & \multirow[t]{3}{*}{ Compound } & \multirow{3}{*}{$\begin{array}{l}\text { Molecular } \\
\text { formula }\end{array}$} & \multirow{3}{*}{$\begin{array}{l}\mathrm{RT} \\
(\mathrm{min})\end{array}$} & \multirow{3}{*}{$\begin{array}{l}\mathrm{m} / \mathrm{z} \\
\text { calcd }\end{array}$} & \multirow{3}{*}{$\begin{array}{l}\mathrm{m} / \mathrm{z} \\
\text { exptl }\end{array}$} & \multirow{3}{*}{$\begin{array}{l}\text { Err } \\
{[\mathrm{mDa}]}\end{array}$} & \multirow[t]{3}{*}{ mSigma } & \multirow{3}{*}{$\begin{array}{l}\text { Major } \\
\text { fragments ESI } \\
\text { negative MS/ } \\
\text { MS ions }\end{array}$} & \multicolumn{6}{|c|}{ In vitro faecal fermentation time (h) } \\
\hline & & & & & & & & & \multicolumn{3}{|c|}{ POPP } & \multicolumn{3}{|c|}{ LOPP } \\
\hline & & & & & & & & & 12 & 24 & $\overline{48}$ & 12 & 24 & 48 \\
\hline M23 & Luteolin $^{\text {a }}$ & $\mathrm{C}_{15} \mathrm{H}_{10} \mathrm{O}_{6}$ & 15.9 & 285.0406 & 285.0405 & 0.1 & 0.8 & $\begin{array}{l}124.0187 ; \\
109.0656 \\
285.0414 ; \\
151.0037\end{array}$ & $\mathrm{D}$ & $\mathrm{D}$ & $\mathrm{D}$ & $\mathrm{D}$ & $\mathrm{D}$ & $\mathrm{D}$ \\
\hline
\end{tabular}

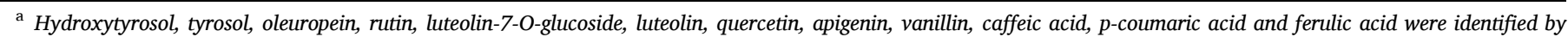

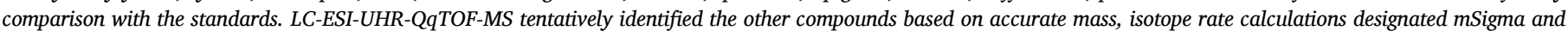
literature.

b Lozano-Sánchez et al. (2013).

c Jerman Klen \& Mozetič Vodopivec(2012).

d Phenol-Explorer 3.6. D - Compound detected; ND - Compound not detected.
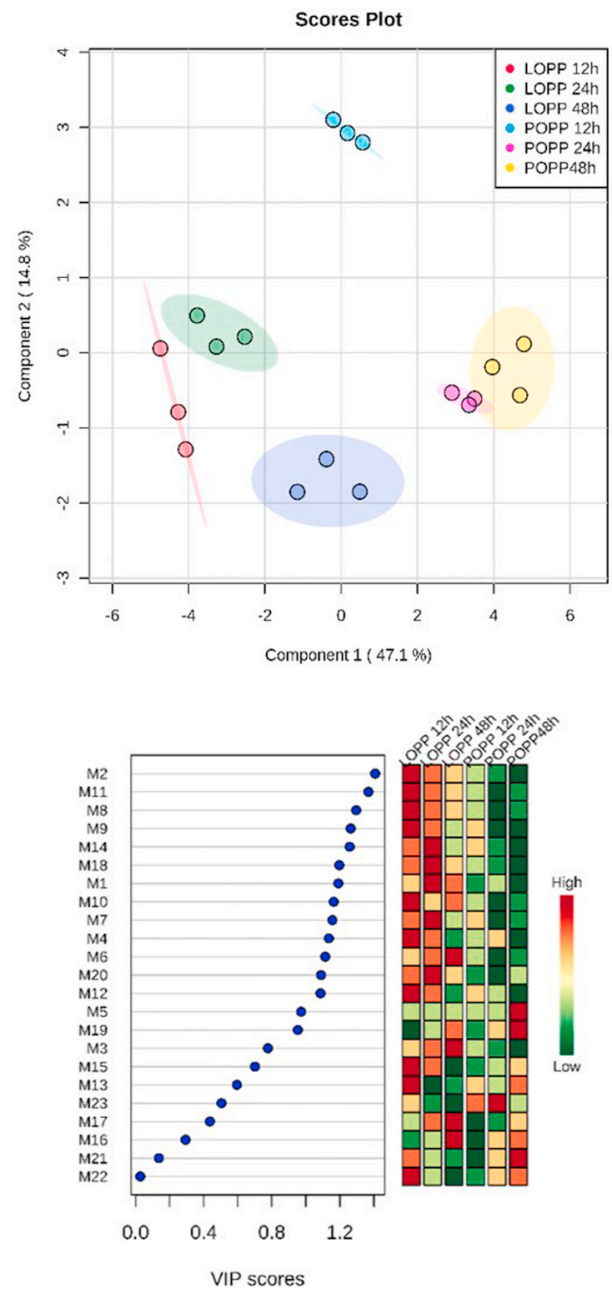

(b)

VIP scores (a)

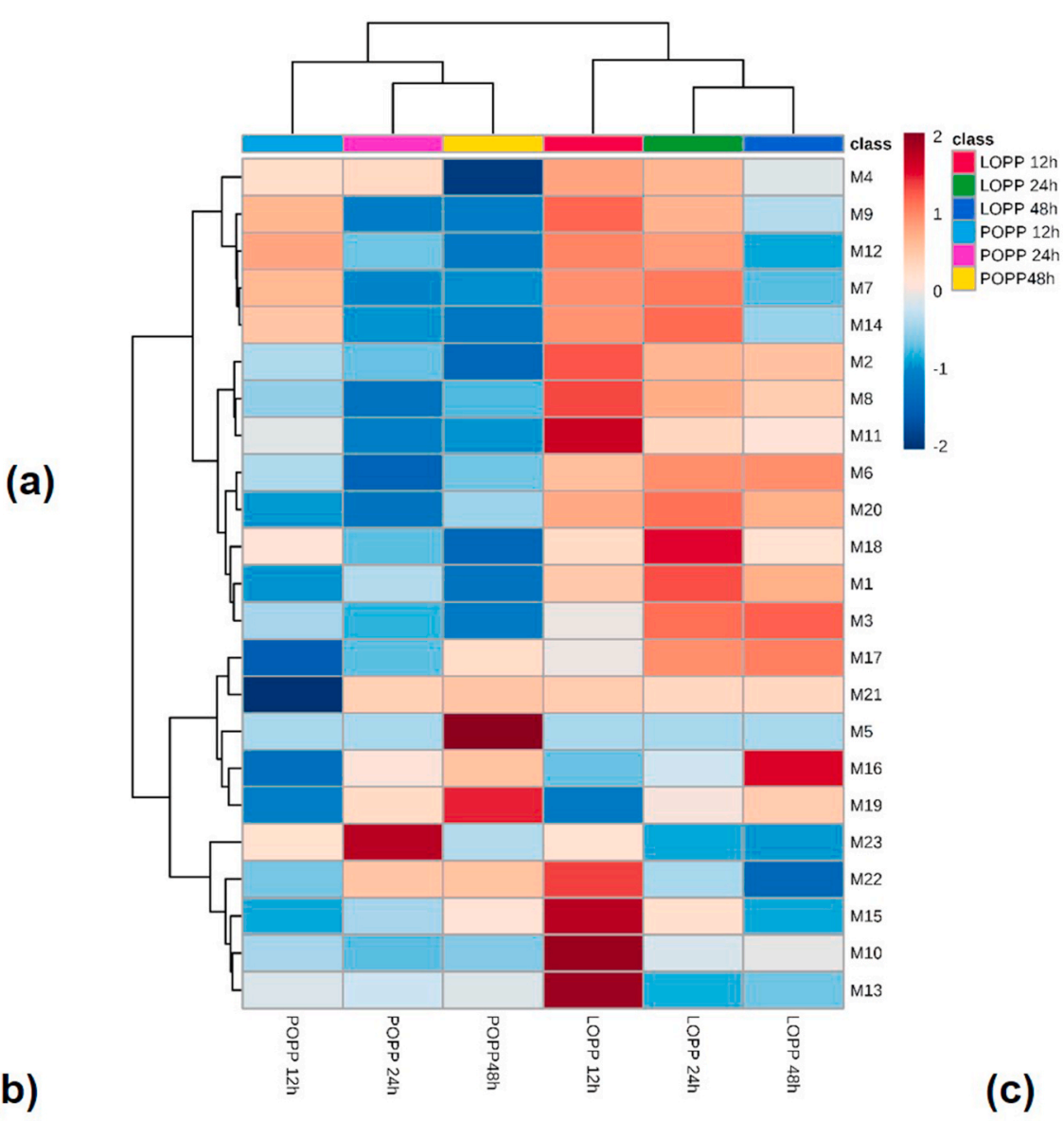

c)

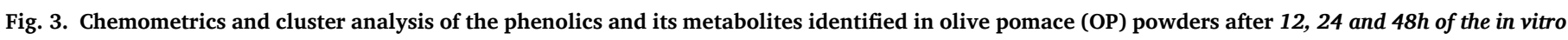

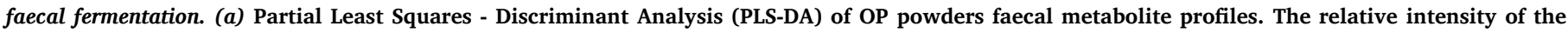

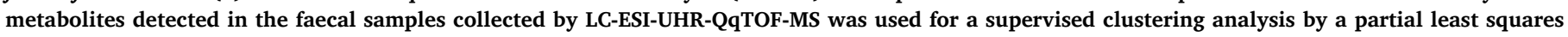

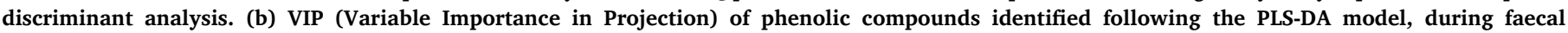

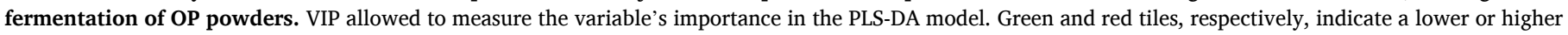

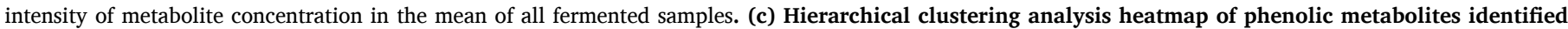

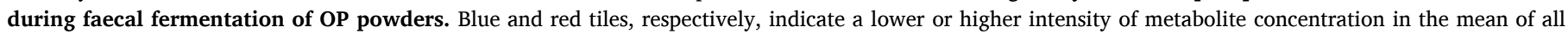
fermented samples. (For interpretation of the references to colour in this figure legend, the reader is referred to the Web version of this article.)

different from the digested LOPP.

The antioxidant capacity (AOX) of the fermented OP powders was determined using the ORAC assay. This method is extensively used to assess the chain-breaking antioxidant capacity at physiological $\mathrm{pH}$ values (Burgos-Edwards et al., 2018). As shown in Fig. 2 b, OP powders exhibited higher AOX than FOS and LOPP revealed the highest AOX ( $p$ $<0.05$ ), following the trend of the TPC values reported. LOPP showed similar AOX between 12 and $24 \mathrm{~h}$ of faecal fermentation, decreasing its AOX value significantly after $48 \mathrm{~h}(p<0.05)$. Previous studies exhibited similar behaviour on the evolution of ORAC. Burgos-Edwards et al. 
(2018) and Rocchetti et al. (2019) also reported similar ORAC values after 8 and $24 \mathrm{~h}$ of faecal fermentation of a polyphenolic-enriched extract of Ribes punctatum currant and pigmented gluten-free flours of red quinoa and black chickpea, respectively. On the other hand, POPP revealed a continuous decline of AOX through in vitro colon fermentation. Burgos-Edwards et al. (2018) and Rocchetti et al. (2019) also reported a similar decrease in ORAC values throughout in vitro colon fermentation of a polyphenolic-enriched extract of Ribes magellanicum currant and pigmented gluten-free flours of teff and amaranth, respectively. Therefore, LOPP revealed to be a more effective source of antioxidant compounds than POPP in the colon.

By comparing the ORAC values obtained in previous works for digested OP powders and those obtained for fermented OP powders, it could be assumed that significant losses of AOX occur during faecal fermentation. Similar results were verified in previous investigations (Burgos-Edwards et al., 2018; Rocchetti et al., 2019). However, other matrices where ORAC values (Burgos-Edwards et al., 2018; Rocchetti et al., 2019) were evaluated after 6 and $8 \mathrm{~h}$ of fermentation exhibited increased ORAC values for a polyphenolic-enriched extract of Chilean currants (Ribes punctatum and Ribes magellanicum). For that reason, the TPC and ORAC assessment in more fermentation time points might be crucial for a superior understanding of the phenolics evolution in a food matrix and its metabolites in the colon. The different trend of ORAC and TPC values observed between digested and fermented OP powders could be explained by the occurrence of different reaction mechanisms of the various antioxidants present in the samples, and has been reported in previous works (Tabart et al., 2010).

In conclusion, OP powders provided a potentially higher prebiotic effect than FOS in terms of health benefits linked to the creation of an antioxidant environment in the gut. OP powders showed to be a valuable source of phenolics with antioxidant activity through in vitro colon fermentation. Future studies in cell lines and human clinical experiments will be required in order to measure the antioxidant effects accurately.

\subsubsection{Identification of phenolic compounds and its metabolites by LC-ESI- UHR-QqTOF-MS}

This study was performed to identify the main molecules generated by the effect of human microbiota acting on different classes of phenolics present in OP powders. The phenolic profile pattern of the analysed fermented OP powders agrees with previous works with OP (Conterno et al., 2019) and olive oil (López de las Hazas et al., 2017; Mosele et al., 2014).

Identification of phenolic precursors and metabolites derived from in vitro microbial colonic fermentation of the OP powders based on highperformance LC-ESI-UHR-QqTOF-MS analyses and a summary of mass spectrometric specific molecular patterns in negative ionisation are summarised in Table 2. Each reported metabolite was detected in at least three of the five different donors after 12,24 or $48 \mathrm{~h}$ of faecal fermentation.

PLS-DA of the phenolic metabolite patterns measured in the samples derived from OP powders fermentation revealed separate clusters for each time of fermentation and sample (Fig. 3 (a)). The scores plot indicates that the first two principal components account for $61.9 \%$ of the total variance $(\mathrm{PC} 1=47.1 \%$ and $\mathrm{PC} 2=14.8 \%$ ). If on the one hand the three clusters of fermentation time of LOPP were positioned close to each other in the III quadrant, on the other hand, the $12 \mathrm{~h}$ fermentationcluster of POPP was located on the I quadrant, and the other clusters of POPP fermentation ( 24 and $48 \mathrm{~h}$ ) were very close to each other in the opposite quadrant (II). Therefore, POPP and LOPP exhibited significant differences in phenolics throughout faecal fermentation, being separated by the most critical factor (PC1), which contributes with $47.1 \%$ of the total variance. Nevertheless, after $48 \mathrm{~h}$ of fermentation, LOPP exhibited a phenolic pattern more similar to that of POPP after 24 and $48 \mathrm{~h}$ of fermentation (LOPP - $48 \mathrm{~h}$ cluster closer to POPP -24 and $48 \mathrm{~h}$ clusters).
Variable importance in projection (VIP) was obtained (Fig. 3 (b)) in order to understand better the differences observed between the different clusters of phenolics from OP powders. Markers assigned a VIP score $>0.8$ were counted as the 15 most significative compounds which define the phenolics patterns of the OP powders trough faecal fermentation. LOPP, as expected, exhibited a higher relative concentration of almost all the phenolic compounds. Hydroxytyrosol glucoside $\left(\mathrm{C}_{14} \mathrm{H}_{20} \mathrm{O}_{8} m z\right.$ 315.1035), hydroxylated product of the dialdehydic form of decarboxymethyl-elenolic acid $\left(\mathrm{C}_{9} \mathrm{H}_{12} \mathrm{O}_{5} \mathrm{mz}\right.$ 199.0564), a decarboxylated form of hydroxyl-elenolic acid $\left(\mathrm{C}_{10} \mathrm{H}_{14} \mathrm{O}_{5} \mathrm{mz} 213.0718\right)$ and 3 - (3,4 - dihydroxyphenyl)-propionic acid $\left(\mathrm{C}_{9} \mathrm{H}_{10} \mathrm{O}_{4} \mathrm{mz}\right.$ 181.0452) were the most significant and at higher relative amounts until $12 \mathrm{~h}$ of LOPP and POPP fermentation (VIP $>1.3$ ). These phenolics decreased throughout in vitro fermentation in both OP powders. On the other hand, oleuropein aglycone derivative $\left(\mathrm{C}_{16} \mathrm{H}_{26} \mathrm{O}_{10} \quad m z\right.$ 377.1353), 3-(4hydroxyphenyl) propionic acid $\left(\mathrm{C}_{9} \mathrm{H}_{10} \mathrm{O}_{3} \mathrm{mz}\right.$ 165.0505) and oxidised hydroxytyrosol $\left(\mathrm{C}_{8} \mathrm{H}_{8} \mathrm{O}_{3} m z 151.0352\right)$ increased after $24 \mathrm{~h}$ of LOPP fermentation (VIP $>1.2$ ). However, in POPP after $24 \mathrm{~h}$ of fermentation, only oxidised hydroxytyrosol increased, while the oleuropein aglycone derivative and 3-(2-hydroxyphenyl) propionic acid decreased. Other phenolic acids metabolites identified in LOPP after $24 \mathrm{~h}$ of fermentation at higher relative concentration were 3-hydroxy-4-methoxyphenyllactic acid $\left(\mathrm{C}_{10} \mathrm{H}_{12} \mathrm{O}_{5} \mathrm{mz}\right.$ 211.0560) (VIP $>1.1$ ) and 3 - (3-hydroxyphenilpropionic acid) $\left(\mathrm{C}_{9} \mathrm{H}_{10} \mathrm{O}_{3} \mathrm{mz}\right.$ 165.0489) (VIP > 0.95). The 3-(3hydroxyphenilpropionic acid) also increased in POPP fermentation until $48 \mathrm{~h}$ of fermentation, and even at a higher rate than in fermented LOPP. Vanillyl alcohol $\left(\mathrm{C}_{8} \mathrm{H}_{10} \mathrm{O}_{3} \mathrm{mz}\right.$ 153.0493) was other metabolite identified (VIP > 0.97) at higher concentration in fermented POPP after $48 \mathrm{~h}$. Other phenolic acids' metabolites were also identified in POPP and LOPP with low VIP (between 0.3 and 0.1), namely homovanillic alcohol $\left(\mathrm{C}_{9} \mathrm{H}_{12} \mathrm{O}_{3} m z\right.$ 167.0655) and homovanillic acid $\left(\mathrm{C}_{9} \mathrm{H}_{10} \mathrm{O}_{4} m z\right.$ 181.0464). All these phenolic acids were reported in previous works with OP biscuits (Conterno et al., 2019) and olive oil (López de las Hazas et al., 2017; Mosele et al., 2014) as colonic metabolites of olive phenolics and precursors of the phenylacetic and phenylpropionic acids. Phenylacetic and phenylpropionic acids have been reported as products from the gut microbial metabolisation of polyphenols with more strong potential health effects, such as anti-inflammatory and antioxidant effects (López de las Hazas et al., 2016), as well as acting as prebiotics inhibiting pathogenic bacteria and stimulating the beneficial bacteria on the colon (KarkovićMarković et al., 2019).

Hierarchical clustering (HCA) of the relative intensity of the 23 phenolic metabolites analysed following the faecal fermentation of OP powders is presented in Fig. 3 (c). The heatmap shows the clustering of phenolic metabolites according to their detection in faecal fermentation samples of OP powders. The clustering of the different phenolic metabolites could be divided into two main principal clusters. These clusters allowed to understand the possible colonic transformations of OP dietary polyphenols into phenolic acids. For example, oleuropein aglycone (M14), hydroxytyrosol (M6), 3-(3,4-dihydroxyphenyl)propionic acid (M9), 3,4-dihydroxybenzoic acid (M4) and 3-(4'-hydroxyphenyl) propionic acid (M18) were detected in the same principal cluster.

The formation of aglycones by gut microbiota has been reported before as affecting positively or negatively, their activities and functional effects (Laparra \& Sanz, 2010). In this work, oleuropein aglycon showed to be a key compound in the colonic phenolic pathway of OP powders. Most of the identified phenolic metabolites could be obtained by the proposed colonic pathway of oleuropein (Mosele et al., 2014). The oleuropein aglycone (M14) through hydrolysis could generate 3-(3', 4'-dihydroxyphenyl)propionic acid (M9) and hydroxytyrosol (M6), and then 3 -( $3^{\prime}, 4^{\prime}$-dihydroxyphenyl) propionic acid (M9) could be transformed into 3,4-dihydroxybenzoic acid (M4) or 3-(4'-hydroxyphenyl) propionic acid (M18) by $\beta$ oxidation and dihydroxylation, respectively. Instead, the colonic pathway of hydroxytyrosol proposed by Mosele et al. (2014) could also enlighten the detection of the 4-dihydroxybenzoic acid metabolite, which could be found after two successive 
Table 3

Antiadhesion activity of OP powders after gastrointestinal digestion.

\begin{tabular}{|c|c|c|c|c|c|}
\hline \multirow[t]{3}{*}{ Pathogenic strain } & \multicolumn{5}{|l|}{ Sample } \\
\hline & \multirow{2}{*}{$\frac{\text { Blank }}{\log (\mathrm{Cfu} / \mathrm{mL})}$} & \multicolumn{2}{|l|}{ POPP } & \multicolumn{2}{|l|}{ LOPP } \\
\hline & & $\log (\mathrm{Cfu} / \mathrm{mL})$ & Antiadhesion activity (\%) & $\log (\mathrm{Cfu} / \mathrm{mL})$ & Antiadhesion activity (\%) \\
\hline Bacillus cereus & $5.23 \pm 0.17$ & $4.26 \pm 0.35$ & $22.03 \pm 2.45$ & $5.14 \pm 0.15$ & $2.86 \pm 0.04$ \\
\hline Listeria monocytogenes & $6.76 \pm 0.30$ & $5.42 \pm 0.35$ & $20.01 \pm 1.93$ & $6.46 \pm 0.26$ & $4.54 \pm 1.12$ \\
\hline Escherichia coli & $6.06 \pm 0.03$ & $6.19 \pm 0.04$ & Not detected & $5.93 \pm 0.07$ & $1.43 \pm 0.27$ \\
\hline Yersinia enterocolitica & $6.44 \pm 0.14$ & $6.22 \pm 0.15$ & $3.51 \pm 0.29$ & $6.06 \pm 0.07$ & $5.98 \pm 1.03$ \\
\hline
\end{tabular}

oxidations reactions: hydroxytyrosol (hydroxytyrosol (M6) oxidation into 2-(3',4'-dihydroxyphenyl)acetic acid which produce 3,4-dihydroxybenzoic acid (M4) by $\alpha$-oxidation. The higher relative concentration and VIP of 3-(4'-hydroxyphenyl)propionic acid (M18) compared to 3,4-dihydroxybenzoic acid (M4) allowed to hypothesise that the dihydroxylation of 3-(4'-hydroxyphenyl)propionic acid (M18) into 3-(3',4'-dihydroxyphenyl) propionic acid (M9) was privileged during colonic fermentation of OP powders.

In the other principal cluster, homovanillic acid (M22), homovanillic alcohol (M21), vanillyl alcohol (M5) and 3-hydroxyphenilpropionic acid (M19) metabolites were detected in growing relative concentrations throughout in vitro faecal fermentation, mostly in fermented POPP. These compounds could result from the metabolisation of hydroxytyrosol. In previous works, hydroxytyrosol was converted to homovanillic alcohol (M21) in Caco-2 cells, and homovanillic acid (M22) and homovanillic alcohol (M21) were detected in urine after metabolisation of hydroxytyrosol supplied by olive oil consumption (Naczk \& Shahidi, 2003). Homovanillic acid (M22) increase was also reported in previous work, after ingestion of OP biscuits (in plasma) (Conterno et al., 2019). On the other hand, the vanillyl alcohol (M5) and 3-hydroxyphenilpropionic acid (M19) could result from biotransformation of vanillin and caffeic acid, respectively.

The metabolites compounds identified in LOPP and POPP derived mainly from the breakdown pathways of the oleuropein aglycon and hydroxytyrosol present in significant amount in these OP powders, principally in LOPP. Therefore, LOPP exhibited a higher relative concentration of phenolic acids metabolites than POPP, in agreement with TPC and ORAC Results. Other metabolic pathways could also take place during POPP colonic fermentation, taking in consideration the metabolites identified in these samples. All steps of the potential metabolic pathways identified during in vitro fermentation of OP powders intermediated by the gut microbiota and its catabolites and similar small phenolic acids have been reported to be excreted following ingestion of olive or olive fractions in previous studies (Conterno et al., 2019).

\subsection{Antiadhesion ability in mucin}

The antiadhesion ability of OP powders $(2 \% \mathrm{~m} / \mathrm{v})$ relative to food contaminant/pathogenic bacteria is reported in Table 3 . However, it is essential to clarify that the inhibition of bacterial adhesion can be the result of various mechanisms such as cell surface modification, quorum sensing, or changes in the cell structure that are not directly connected with the antibacterial activity of the tested substance (Vunduk et al., 2019).

The Results are expressed as \% of adhesion prevention in comparison with the control sample (bacteria adhered without the presence of tested samples). Results are the means of three determinations \pm standard deviation.

Our study showed that OP powders exhibited antiadhesion activity towards almost all bacteria, varying between 1.4 and $22 \%$. The most pronounced effect was detected for POPP against Gram-positive bacteria. Bacillus cereus $(22.03 \pm 2.45 \%)$ and Listeria monocytogenes $(20.01 \pm$ 1.93) adhesions were inhibited at least at $20 \%$. POPP is mostly composed by insoluble fibre, but it also contains a considerable amount of free and bound phenolic compounds, which may act as anti-adhesion agents (Supplementary material A3). Luteolin, for example, it was retained in higher amounts in POPP undigested fraction and has been described to possess antimicrobial activity against several bacterial species (Aziz et al., 2018; Sousa et al., 2006).

LOPP displayed a weaker antiadhesion activity against Grampositive bacteria (2.86-4.54\%) than POPP but demonstrated a higher capacity to inhibit the adhesion of Gram-negative bacteria. LOPP exhibited a low capacity to inhibit the adhesion of Escherichia coli (1.43 $\pm 0.27 \%$ ) and the double of the capacity of POPP from inhibiting the adhesion of Yersinia enterocolitica $(5.98 \pm 1.03 \%)$. Its phenolic profile could explain the lower antiadhesion activity of LOPP despite its higher phenolics content. When comparing LOPP and POPP phenolic profile, it can be concluded that LOPP retained higher amounts of tyrosol and tyrosol glucoside in the colon after digestion (Supplementary material A3). However, tyrosol was reported as the least antimicrobial active phenolic molecule from secoiridoid breakdown in Olea europaea (Thielmann et al., 2017). On the other hand, the low but higher capacity of LOPP to inhibit Gram-negative bacteria could result from synergistic effects of polyphenolic compounds and other non-phenolic compounds such as minerals (Costa et al., 2019) and organic acids (Östling \& Lindgren, 1993) (Supplementary material A3).

In the present study, only one concentration was tested $(2 \% \mathrm{~m} / \mathrm{v})$ to evaluate the antiadhesion capacity and potential prebiotic effect of OP powders simultaneously. However, other concentrations could be tested to clarify a possible dose-dependent inhibition activity.

\section{Conclusion}

Prebiotics are defined as substances that induce the growth or metabolic activity of microorganisms that contribute to the well-being of their host. In this sense, olive pomace powders showed to confer health benefits to the gastrointestinal tract as promoters of the production of short-chain fatty acids by gut microbiota in a higher degree than fructooligosaccharides, thus contributing to the improvement of several health effects. Equally, olive pomace powders were shown to be a significant source of phenolics metabolites after LC-ESI-UHR-QqTOF-MS detection. Supervised cluster and hierarchical clustering analysis allowed to evaluate the metabolite patterns of olive pomace powders phenolics throughout in vitro faecal fermentation, explaining the potential antioxidant activity and antiadhesion ability against food pathogens discovered to these powders. Other potential gut health benefits could also be expected to olive pomace powders.

The development of new prebiotics and/or gut-health-benefits powders from olive pomace could be an opportunity of adding value to the higher by-product stream from the modern olive oil production. However, before the development of added value secondary product lines, future studies using $\mathrm{pH}$ control, cell lines or even clinical studies are needed to clarify the potential prebiotic health benefits of olive pomace powders.

\section{CRediT authorship contribution statement}

Tânia Bragança Ribeiro: Conceptualization, Investigation, Formal analysis, Writing - original draft. Célia Maria Costa: Validation, Investigation. Teresa Bonifácio - Lopes: Investigation. Sara Silva: 
Investigation. Mariana Veiga: Investigation. Ana Rita Monforte: Formal analysis. João Nunes: Supervision, Writing - review \& editing. António A. Vicente: Supervision, Writing - review \& editing. Manuela Pintado: Resources, Validation, Supervision, Conceptualization, Writing - review \& editing.

\section{Declaration of comprting interests}

The authors declare that they have no known competing financial interests or personal relationships that could have appeared to influence the work reported in this paper.

\section{Acknowledgements}

Tânia I. B. Ribeiro thanks the FCT - Fundação para a Ciência e Tecnologia, Portugal and Association BLC3 - Technology and Innovation Campus, Centre Bio R\&D Unit for the PhD Grant SFRH/BDE/108271/ 2015. This work was supported by National Funds from FCT - Fundação para a Ciência e a Tecnologia, Portugal through the project MULTIBIOREFINERY - SAICTPAC/0040/2015 (POCI-01-0145-FEDER016403). We would also like to thank the scientific collaboration under the FCT project UID/Multi/50016/2019.

\section{Appendix A. Supplementary data}

Supplementary data related to this article can be found at https:// doi.org/10.1016/j.foodhyd.2020.106312.

\section{References}

Abenavoli, L., Scarpellini, E., Colica, C., Boccuto, L., Salehi, B., Sharifi-Rad, J., Aiello, V., Romano, B., De Lorenzo, A., Izzo, A. A., \& Capasso, R. (2019). Gut microbiota and obesity: A role for probiotics. Nutrients, 11(11), 2690. https://doi.org/10.3390/ nu11112690.

Aponte, M., Ungaro, F., d'Angelo, I., De Caro, C., Russo, R., Blaiotta, G., Dal Piaz, F., Calignano, A., \& Miro, A. (2018). Improving in vivo conversion of oleuropein into hydroxytyrosol by oral granules containing probiotic Lactobacillus plantarum $299 \mathrm{v}$ and an Olea europaea standardized extract. International Journal of Pharmaceutics, 543(1-2), 73-82. https://doi.org/10.1016/j.ijpharm.2018.03.013.

Arranz, S., Silván, J. M., \& Saura-Calixto, F. (2010). Nonextractable polyphenols, usually ignored, are the major part of dietary polyphenols: A study on the Spanish diet. Molecular Nutrition \& Food Research, 54(11), 1646-1658. https://doi.org/10.1002/ mnfr.200900580.

Aziz, N., Kim, M.-Y., \& Cho, J. Y. (2018). Anti-inflammatory effects of luteolin: A review of in vitro, in vivo, and in silico studies. Journal of Ethnopharmacology, 225, 342-358. https://doi.org/10.1016/j.jep.2018.05.019.

Bao, T., Li, Y., Xie, J., Jia, Z., \& Chen, W. (2019). Systematic evaluation of polyphenols composition and antioxidant activity of mulberry cultivars subjected to gastrointestinal digestion and gut microbiota fermentation. Journal of Functional Foods, 58(866), 338-349. https://doi.org/10.1016/j.jff.2019.05.017.

Belenguer, A., Duncan, S. H., Holtrop, G., Anderson, S. E., Lobley, G. E., \& Flint, H. J. (2007). Impact of $\mathrm{pH}$ on lactate formation and utilization by human fecal microbial communities. Applied and Environmental Microbiology, 73(20), 6526-6533. https:// doi.org/10.1128/AEM.00508-07.

Burgos-Edwards, A., Jiménez-Aspee, F., Theoduloz, C., \& Schmeda-Hirschmann, G. (2018). Colonic fermentation of polyphenols from Chilean currants (Ribes spp.) and its effect on antioxidant capacity and metabolic syndrome-associated enzymes. Food Chemistry, 258, 144-155. https://doi.org/10.1016/j.foodchem.2018.03.053.

Cockburn, D. W., \& Koropatkin, N. M. (2016). Polysaccharide degradation by the intestinal microbiota and its influence on human health and disease. Journal of Molecular Biology, 428(16), 3230-3252. https://doi.org/10.1016/j. jmb.2016.06.021.

Conterno, L., Martinelli, F., Tamburini, M., Fava, F., Mancini, A., Sordo, M., Pindo, M., Martens, S., Masuero, D., Vrhovsek, U., Dal Lago, C., Ferrario, G., Morandini, M., \& Tuohy, K. (2019). Measuring the impact of olive pomace enriched biscuits on the gut microbiota and its metabolic activity in mildly hypercholesterolaemic subjects. European Journal of Nutrition, 58(1), 63-81. https://doi.org/10.1007/s00394-0171572-2.

Costa, J. R., Amorim, M., Vilas-Boas, A., Tonon, R. V., Cabral, L. M. C., Pastrana, L., \& Pintado, M. (2019). Impact of in vitro gastrointestinal digestion on the chemical composition, bioactive properties, and cytotoxicity of Vitis vinifera L. cv. Syrah grape pomace extract. Food \& Function, 10(4), 1856-1869. https://doi.org/10.1039/ C8FO02534G.

Cummings, J. H. (1981). Short chain fatty acids in the human colon. Gut, 22(9), 763-779. https://doi.org/10.1136/gut.22.9.763.

De Vuyst, L., \& Leroy, F. (2011). Cross-feeding between bifidobacteria and butyrateproducing colon bacteria explains bifdobacterial competitiveness, butyrate production, and gas production. International Journal of Food Microbiology, 149(1), 73-80. https://doi.org/10.1016/j.ijfoodmicro.2011.03.003.

Dominika, Ś., Arjan, N., Karyn, R. P., \& Henryk, K. (2011). The study on the impact of glycated pea proteins on human intestinal bacteria. International Journal of Food Microbiology, 145(1), 267-272. https://doi.org/10.1016/j.ijfoodmicro.2011.01.002.

Duda-Chodak, A., Tarko, T., Satora, P., \& Sroka, P. (2015). Interaction of dietary compounds, especially polyphenols, with the intestinal microbiota: A review. European Journal of Nutrition, 54(3), 325-341. https://doi.org/10.1007/s00394-0150852-y.

EFSA. (2011). Scientific Opinion on the substantiation of health claims related to polyphenols in olive and protection of LDL particles from oxidative damage (ID 1333, 1638, 1639, 1696, 2865), maintenance of normal blood HDL cholesterol concentrations (ID 1639), mainte. EFSA Journal, 9(4), 2033. https://doi.org/ 10.2903/j.efsa.2011.2033.

Flint, H. J., \& Duncan, S. H. (2014). Bacteroides and Prevotella. In Encyclopedia of food microbiology (Vol. 1, pp. 203-208). Elsevier. https://doi.org/10.1016/B978-0-12384730-0.00031-8. Second Edi.

Galanakis, C. M. (2011). Olive fruit dietary fiber: Components, recovery and applications. Trends in Food Science \& Technology, 22(4), 175-184. https://doi.org/ 10.1016/j.tifs.2010.12.006.

Gibson, G. R., Hutkins, R., Sanders, M. E., Prescott, S. L., Reimer, R. A., Salminen, S. J., Scott, K., Stanton, C., Swanson, K. S., Cani, P. D., Verbeke, K., \& Reid, G. (2017). Expert consensus document: The International Scientific Association for Probiotics and Prebiotics (ISAPP) consensus statement on the definition and scope of prebiotics. Nature Reviews Gastroenterology \& Hepatology. https://doi.org/10.1038/ nrgastro.2017.75.

Gullón, B., Gullón, P., Tavaria, F., Pintado, M., Gomes, A. M., Alonso, J. L., \& Parajó, J. C. (2014). Structural features and assessment of prebiotic activity of refined arabinoxylooligosaccharides from wheat bran. Journal of Functional Foods, 6, 438-449. https://doi.org/10.1016/j.jff.2013.11.010.

Gullon, B., Pintado, M. E., Fernández-López, J., Pérez-Álvarez, J. A., \& Viuda-Martos, M. (2015). In vitro gastrointestinal digestion of pomegranate peel (Punica granatum) flour obtained from co-products: Changes in the antioxidant potential and bioactive compounds stability. Journal of Functional Foods, 19, 617-628. https://doi.org/ 10.1016/j.jff.2015.09.056.

Haddadin, M. S. Y. (2010). Effect of olive leaf extracts on the growth and metabolism of two probiotic bacteria of intestinal origin. Pakistan Journal of Nutrition, 9(8), 787-793. https://doi.org/10.3923/pjn.2010.787.793.

Jerman Klen, T., \& Mozetič Vodopivec, B. (2012). The fate of olive fruit phenols during commercial olive oil processing: Traditional press versus continuous two- and threephase centrifuge. Lebensmittel-Wissenschaft und -Technologie- Food Science and Technology, 49(2), 267-274. https://doi.org/10.1016/j.lwt.2012.03.029.

Jiao, X., Wang, Y., Lin, Y., Lang, Y., Li, E., Zhang, X., Zhang, Q., Feng, Y., Meng, X., \& $\mathrm{Li}$, B. (2019). Blueberry polyphenols extract as a potential prebiotic with anti-obesity effects on C57BL/ $6 \mathrm{~J}$ mice by modulating the gut microbiota. Journal of Nutritional Biochemistry, 64, 88-100. https://doi.org/10.1016/j.jnutbio.2018.07.008.

Karković Marković, A., Torić, J., Barbarić, M., \& Jakobušić Brala, C. (2019). Hydroxytyrosol, tyrosol and derivatives and their potential effects on human health. Molecules, 24(10). https://doi.org/10.3390/molecules24102001, 2001.

Koh, A., De Vadder, F., Kovatcheva-Datchary, P., \& Bäckhed, F. (2016). From dietary fiber to host physiology: Short-chain fatty acids as key bacterial metabolites. Cell, 165(6), 1332-1345. https://doi.org/10.1016/j.cell.2016.05.041.

Koliada, A., Syzenko, G., Moseiko, V., Budovska, L., Puchkov, K., Perederiy, V., Gavalko, Y., Dorofeyev, A., Romanenko, M., Tkach, S., Sineok, L., Lushchak, O., \& Vaiserman, A. (2017). Association between body mass index and Firmicutes/ Bacteroidetes ratio in an adult Ukrainian population. BMC Microbiology, 17(1), 120. https://doi.org/10.1186/s12866-017-1027-1.

Kovatcheva-Datchary, P., Nilsson, A., Akrami, R., Lee, Y. S., De Vadder, F., Arora, T. Hallen, A., Martens, E., Björck, I., \& Bäckhed, F. (2015). Dietary fiber-induced improvement in glucose metabolism is associated with increased abundance of Prevotella. Cell Metabolism, 22(6), 971-982. https://doi.org/10.1016/j. cmet.2015.10.001.

Kowlgi, N. G., \& Chhabra, L. (2015). D-lactic acidosis: An underrecognized complication of short bowel syndrome, 2015 Gastroenterology Research and Practice, 1-8. https:// doi.org/10.1155/2015/476215.

Laparra, J. M., \& Sanz, Y. (2010). Interactions of gut microbiota with functional food components and nutraceuticals. Pharmacological Research, 61(3), 219-225. https:// doi.org/10.1016/j.phrs.2009.11.001.

Lattimer, J. M., \& Haub, M. D. (2010). Effects of dietary fiber and its components on metabolic health. Nutrients, 2(12), 1266-1289. https://doi.org/10.3390/ nu2121266.

Liehr, M., Mereu, A., Pastor, J. J., Carlos Quintela, J., Staats, S., Rimbach, G., \& Ipharraguerre, I. R. (2017). Olive oil bioactives protect pigs against experimentallyinduced chronic inflammation independently of alterations in gut microbiota. https://doi. org/10.1371/journal.pone.0174239.

López de las Hazas, M. C., Piñol, C., Macià, A., \& Motilva, M.-J. (2017). Hydroxytyrosol and the colonic metabolites derived from virgin olive oil intake induce cell cycle arrest and apoptosis in colon cancer cells. Journal of Agricultural and Food Chemistry, 65(31), 6467-6476. https://doi.org/10.1021/acs.jafc.6b04933.

López de las Hazas, M. C., Piñol, C., Macià, A., Romero, M.-P., Pedret, A., Solà, R., Rubió, L., \& Motilva, M.-J. (2016). Differential absorption and metabolism of hydroxytyrosol and its precursors oleuropein and secoiridoids. Journal of Functional Foods, 22, 52-63. https://doi.org/10.1016/j.jff.2016.01.030.

Louis, P., Duncan, S. H., McCrae, S. I., Millar, J., Jackson, M. S., \& Flint, H. J. (2004). Restricted distribution of the butyrate kinase pathway among butyrate-producing 
bacteria from the human colon. Journal of Bacteriology, 186(7), 2099-2106. https:// doi.org/10.1128/JB.186.7.2099-2106.2004.

Louis, P., McCrae, S. I., Charrier, C., \& Flint, H. J. (2007). Organization of butyrate synthetic genes in human colonic bacteria: Phylogenetic conservation and horizontal gene transfer. FEMS Microbiology Letters, 269(2), 240-247. https://doi.org/10.1111/ j.1574-6968.2006.00629.x.

Lozano-Sánchez, J., Bendini, A., Quirantes-Piné, R., Cerretani, L., Segura-Carretero, A., \& Fernández-Gutiérrez, A. (2013). Monitoring the bioactive compounds status of extravirgin olive oil and storage by-products over the shelf life. Food Control, 30(2), 606-615. https://doi.org/10.1016/j.foodcont.2012.06.036.

Maekawa, M., Ushida, K., Hoshi, S., Kashima, N., Ajisaka, K., \& Yajima, T. (2009). Butyrate and propionate production from D-mannitol in the large intestine of pig and rat. https://doi.org/10.1080/08910600500430730.

Mannelli, F., Cappucci, A., Pini, F., Pastorelli, R., Decorosi, F., Giovannetti, L., Mele, M., Minieri, S., Conte, G., Pauselli, M., Rapaccini, S., Viti, C., \& Buccioni, A. (2018). Effect of different types of olive oil pomace dietary supplementation on the rumen microbial community profile in Comisana ewes. Scientific Reports, 8(1), 8455. https://doi.org/10.1038/s41598-018-26713-w.

Marques, C., Meireles, M., Norberto, S., Leite, J., Freitas, J., Pestana, D., Faria, A., \& Calhau, C. (2016). High-fat diet-induced obesity rat model: A comparison between wistar and sprague-dawley rat. Adipocyte, 5(1), 11-21. https://doi.org/10.1080/ 21623945.2015.1061723.

Monforte, A. R., Martins, S. I. F. S., \& Silva Ferreira, A. C. (2018). Strecker aldehyde formation in wine: New insights into the role of gallic acid, glucose, and metals in phenylacetaldehyde formation. Journal of Agricultural and Food Chemistry, 66(10), 2459-2466. https://doi.org/10.1021/acs.jafc.7b00264.

Mosele, J. I., Martín-Peláez, S., Macià, A., Farràs, M., Valls, R.-M., Catalán, Ú., \& Motilva, M.-J. (2014). Faecal microbial metabolism of olive oil phenolic compounds: In vitro and in vivo approaches. Molecular Nutrition \& Food Research, 58(9), 1809-1819. https://doi.org/10.1002/mnfr.201400124.

Naczk, M., \& Shahidi, F. (2003). Chapter 7 - nutritional and pharmacological effects of food phenolics. Phenolics in food and nutraceuticals. CRC Press. https://doi.org/ 10.1201/9780203508732.ch8.

Nunes, M. A., Pimentel, F. B., Costa, A. S. G., Alves, R. C., \& Oliveira, M. B. P. P. (2016) Olive by-products for functional and food applications: Challenging opportunities to face environmental constraints. Innovative Food Science \& Emerging Technologies, 35, 139-148. https://doi.org/10.1016/j.ifset.2016.04.016.

Oliveira, A., Alexandre, E. M. C., Coelho, M., Barros, R. M., Almeida, D. P. F., \& Pintado, M. (2016). Peach polyphenol and carotenoid content as affected by frozen storage and pasteurization. Lebensmittel-Wissenschaft und -Technologie- Food Science and Technology, 66, 361-368. https://doi.org/10.1016/j.lwt.2015.10.037.

Östling, C. E., \& Lindgren, S. E. (1993). Inhibition of enterobacteria and Listeria growth by lactic, acetic and formic acids. Journal of Applied Bacteriology, 75(1), 18-24. https://doi.org/10.1111/j.1365-2672.1993.tb03402.x.

Papillo, V. A., Vitaglione, P., Graziani, G., Gokmen, V., \& Fogliano, V. (2014). Release of antioxidant capacity from five plant foods during a multistep enzymatic digestion protocol. Journal of Agricultural and Food Chemistry, 62(18), 4119-4126. https://doi. org/10.1021/jf500695a.

Parkar, S. G., Trower, T. M., \& Stevenson, D. E. (2013). Fecal microbial metabolism of polyphenols and its effects on human gut microbiota. Anaerobe, 23(August), 12-19. https://doi.org/10.1016/j.anaerobe.2013.07.009.

Pouteau, E., Dumon, H., Nguyen, P., Darmaun, D., Champ, M., \& Krempf, M. (1998). Whole-body, peripheral and intestinal endogenous acetate turnover in dogs using stable isotopes. Journal of Nutrition, 128(1), 111-115. https://doi.org/10.1093/jn/ 128.1.111.

Ribeiro, T. B., Oliveira, A., Campos, D., Nunes, J., Vicente, A. A., \& Pintado, M. (2020). Simulated digestion of an olive pomace water-soluble ingredient: Relationship between the bioaccessibility of compounds and their potential health benefits. Food \& Function, 11(3), 2238-2254. https://doi.org/10.1039/C9FO03000J.

Ríos-Covián, D., Ruas-Madiedo, P., Margolles, A., Gueimonde, M., de los ReyesGavilán, C. G., \& Salazar, N. (2016a). Intestinal short chain fatty acids and their link with diet and human health. Frontiers in Microbiology, 7(FEB), 1-9. https://doi.org/ 10.3389/fmicb.2016.00185.

Ríos-Covián, D., Ruas-Madiedo, P., Margolles, A., Gueimonde, M., de los ReyesGavilán, C. G., \& Salazar, N. (2016b). Intestinal short chain fatty acids and their link with diet and human health. Frontiers in Microbiology, 7, 185. https://doi.org/ 10.3389/fmicb.2016.00185.

Robles-Almazan, M., Pulido-Moran, M., Moreno-Fernandez, J., Ramirez-Tortosa, C., Rodriguez-Garcia, C., Quiles, J. L., \& Ramirez-Tortosa, Mc (2018). Hydroxytyrosol: Bioavailability, toxicity, and clinical applications. In Food research international (Vol. 105, pp. 654-667). Elsevier Ltd. https://doi.org/10.1016/j.foodres.2017.11.053.

Rocchetti, G., Chiodelli, G., Giuberti, G., Ghisoni, S., Baccolo, G., Blasi, F., Montesano, D., Trevisan, M., \& Lucini, L. (2018). UHPLC-ESI-QTOF-MS profile of polyphenols in Goji berries (Lycium barbarum L.) and its dynamics during in vitro gastrointestinal digestion and fermentation. Journal of Functional Foods, 40, 564-572. https://doi. $\operatorname{org} / 10.1016 /$ j.jff.2017.11.042.
Rocchetti, G., Lucini, L., Giuberti, G., Bhumireddy, S. R., Mandal, R., Trevisan, M., \& Wishart, D. S. (2019). Transformation of polyphenols found in pigmented gluten-free flours during in vitro large intestinal fermentation. Food Chemistry, 298, 125068. https://doi.org/10.1016/j.foodchem.2019.125068. October 2018.

Rui, Y., Wan, P., Chen, G., Xie, M., Sun, Y., Zeng, X., \& Liu, Z. (2019). Simulated digestion and fermentation in vitro by human gut microbiota of intra- and extra-cellular polysaccharides from Aspergillus cristatus. LWT, 116. https://doi.org/10.1016/j. lwt.2019.108508.

Santos, M. M., Piccirillo, C., Castro, P. M. L., Kalogerakis, N., \& Pintado, M. E. (2012). Bioconversion of oleuropein to hydroxytyrosol by lactic acid bacteria. World Journal of Microbiology and Biotechnology, 28(6), 2435-2440. https://doi.org/10.1007/ s11274-012-1036-z.

Sato, Y., Itagaki, S., Kurokawa, T., Ogura, J., Kobayashi, M., Hirano, T., Sugawara, M., \& Iseki, K. (2011). In vitro and in vivo antioxidant properties of chlorogenic acid and caffeic acid. International Journal of Pharmaceutics, 403(1-2), 136-138. https://doi. org/10.1016/j.ijpharm.2010.09.035.

Scott, K. P., Gratz, S. W., Sheridan, P. O., Flint, H. J., \& Duncan, S. H. (2013). The influence of diet on the gut microbiota. Pharmacological Research, 69(1), 52-60. https://doi.org/10.1016/j.phrs.2012.10.020.

Seong, H., Bae, J. H., Seo, J. S., Kim, S. A., Kim, T. J., \& Han, N. S. (2019). Comparative analysis of prebiotic effects of seaweed polysaccharides laminaran, porphyran, and ulvan using in vitro human fecal fermentation. Journal of Functional Foods, 57(April), 408-416. https://doi.org/10.1016/j.jff.2019.04.014.

Simpson, H. L., \& Campbell, B. J. (2015). Review article: Dietary fibre-microbiota interactions. Alimentary Pharmacology and Therapeutics, 42(2), 158-179. https://doi. org/10.1111/apt.13248.

Singleton, V. L., \& Rossi, J. A. (1965). Colorimetry of total phenolics with phosphomolybdic-phosphotungstic acid reagents. American Journal of Enology and Viticulture, 16(3). http://www.ajevonline.org/content/16/3/144.

Sousa, A., Ferreira, I. C. F. R., Calhelha, R., Andrade, P. B., Valentão, P., Seabra, R. Estevinho, L., Bento, A., \& Pereira, J. A. (2006). Phenolics and antimicrobial activity of traditional stoned table olives "alcaparra. Bioorganic \& Medicinal Chemistry, 14 (24), 8533-8538. https://doi.org/10.1016/j.bmc.2006.08.027.

Tabart, J., Kevers, C., Pincemail, J., Defraigne, J.-O., \& Dommes, J. (2010). Evaluation of spectrophotometric methods for antioxidant compound measurement in relation to total antioxidant capacity in beverages. Food Chemistry, 120(2), 607-614. https:// doi.org/10.1016/j.foodchem.2009.10.031.

Tabernero, M., \& Gómez de Cedrón, M. (2017). Microbial metabolites derived from colonic fermentation of non-digestible compounds. Current Opinion in Food Science, 13, 91-96. https://doi.org/10.1016/j.cofs.2017.03.005.

Thielmann, J., Kohnen, S., \& Hauser, C. (2017). Antimicrobial activity of Olea europaea Linné extracts and their applicability as natural food preservative agents. International Journal of Food Microbiology, 251, 48-66. https://doi.org/10.1016/j. ijfoodmicro.2017.03.019.

Topping, D. L., \& Clifton, P. M. (2001). Short-chain fatty acids and human colonic function: Roles of resistant starch and nonstarch polysaccharides. Physiological Reviews, 81(Issue 3), 1031-1064. https://doi.org/10.1152/physrev.2001.81.3.1031. American Physiological Society.

Torres-León, C., Ramírez-Guzman, N., Londoño-Hernandez, L., Martinez-Medina, G. A., Díaz-Herrera, R., Navarro-Macias, V., Alvarez-Pérez, O. B., Picazo, B., VillarrealVázquez, M., Ascacio-Valdes, J., \& Aguilar, C. N. (2018). Food waste and byproducts: An opportunity to minimize malnutrition and hunger in developing countries. Frontiers in Sustainable Food Systems, 2(September), 1-17. https://doi.org/10.3389/ fsufs.2018.00052.

Valeriano, V. D., Parungao-Balolong, M. M., \& Kang, D.-K. (2014). In vitro evaluation of the mucin-adhesion ability and probiotic potential of Lactobacillus mucosae LM1. Journal of Applied Microbiology, 117(2), 485-497. https://doi.org/10.1111/ jam.12539.

Vunduk, J., Wan-Mohtar, W. A. A. Q. I., Mohamad, S. A., Abd Halim, N. H., Mohd Dzomir, A. Z., Žižak, Ž., \& Klaus, A. (2019). Polysaccharides of Pleurotus flabellatus strain Mynuk produced by submerged fermentation as a promising novel tool against adhesion and biofilm formation of foodborne pathogens. Lebensmittel-Wissenschaft \& Technologie, 112(April). https://doi.org/10.1016/j.lwt.2019.05.119.

Wang, M., Wichienchot, S., He, X., Fu, X., Huang, Q., \& Zhang, B. (2019). In vitro colonic fermentation of dietary fibers: Fermentation rate, short-chain fatty acid production and changes in microbiota. In Trends in food science and Technology (Vol. 88, pp. 1-9). Elsevier Ltd. https://doi.org/10.1016/j.tifs.2019.03.005.

Williams, B., Grant, L., Gidley, M., \& Mikkelsen, D. (2017). Gut fermentation of dietary fibres: Physico-chemistry of plant cell walls and implications for health. International Journal of Molecular Sciences, 18(10), 2203. https://doi.org/10.3390/ijms18102203.

Ying, D. Y., Hlaing, M. M., Lerisson, J., Pitts, K., Cheng, L., Sanguansri, L., \& Augustin, M. A. (2017). Physical properties and FTIR analysis of rice-oat flour and maize-oat flour based extruded food products containing olive pomace. Food Research International, 100, 665-673. https://doi.org/10.1016/j. foodres.2017.07.062. 